Article

\title{
Interleukins 4 and 13 and Their Receptors Are Differently Expressed in Gastrointestinal Tract Cancers, Depending on the Anatomical Site and Disease Advancement, and Improve Colon Cancer Cell Viability and Motility
}

\author{
Iwona Bednarz-Misa ${ }^{1}$, Dorota Diakowska ${ }^{2,3}{ }^{\oplus}$, Izabela Szczuka ${ }^{1}$, Paulina Fortuna ${ }^{1}{ }^{(}$, \\ Agnieszka Kubiak ${ }^{1}$, Joanna Rosińczuk ${ }^{3}$ (D) and Małgorzata Krzystek-Korpacka ${ }^{1, *(1)}$ \\ 1 Department of Medical Biochemistry, Wroclaw Medical University, 50-368 Wroclaw, Poland; \\ iwona.bednarz-misa@umed.wroc.pl (I.B.-M.); izabela.szczuka@umed.wroc.pl (I.S.); \\ paulina.fortuna@umed.wroc.pl (P.F.); a.kubiak@umed.wroc.pl (A.K.) \\ 2 Department of Gastrointestinal and General Surgery, Wroclaw Medical University, 50-368 Wroclaw, Poland; \\ dorota.diakowska@umed.wroc.pl \\ 3 Department of Nervous System Diseases, Wroclaw Medical University, 51-618 Wroclaw, Poland; \\ joanna.rosinczuk@umed.wroc.pl \\ * Correspondence: malgorzata.krzystek-korpacka@umed.wroc.pl; Tel.: +48-717841395
}

Received: 9 April 2020; Accepted: 1 June 2020; Published: 4 June 2020

check for updates

\begin{abstract}
Immunosuppressive interleukins (IL)-4 and 13 may directly promote cancer but neither their status nor role in gastrointestinal tract is clarified. We aim at quantifying ILs and their receptors in paired normal-tumor samples $(n=49 / 51)$ and sera $(n=263)$, using immunoassays and RTqPCR, and screening for their effect on colonic cancer cells. Both ILs were elevated locally at protein level in all cancers but only IL13 transcripts in colon were upregulated. Interleukin and their receptor expression reflected cancer pathology to varying degrees, with the association frequently inverse and manifested in non-cancerous tissue. Positive correlation with cancer-promoting genes BCL2, BCL $x L$, HIF1A, VEGFA, ACTA2, CCL2, PTGS2, and CDKN1A, but not Ki67, was demonstrated, particularly for ILs' receptors. Circulating IL-4 was elevated in all, while IL-13 only in colorectal or esophageal cancers, reflecting their advancement. IL4R $a$ and IL13Ra1 transcripts were downregulated by hypoxia and, in Caco-2, also by IL-4. Interleukin stimulation slightly improved colonic cancer cell viability, weakly upregulating BCL2 and Ki67 in HCT116 and HT-29. It affected cell motility more markedly and was consistently accompanied by upregulation of claudin-2. Gastrointestinal tract cancers are associated with IL-4 and IL-13 upregulation, which may facilitate cancer growth. Targeting both interleukins as an antineoplastic strategy warrants further investigation.
\end{abstract}

Keywords: colorectal cancer; esophageal squamous cell carcinoma; gastric adenocarcinoma; immunotherapy; molecular margin; interleukin

\section{Introduction}

Cancers of the gastrointestinal tract (GIT), including esophageal squamous cell carcinoma (ESCC), gastric adenocarcinoma (GC), and colorectal adenocarcinoma (CRC), are among the leading causes of death worldwide [1]. CRC alone accounted for an estimated 1,850,000 new cancer cases in 2018 and was the second leading cause of cancer-related deaths [1]. Tumor resection, combined with chemotherapy or radiotherapy, remains the main treatment option but may fail to improve the outcome in patients with metastatic or resistant cancers. Harnessing the immune system to fight cancer is seen 
as an attractive alternative to chemotherapy and radiation as a more precise approach, potentially better tolerated and yielding durable remission [2,3]. However, immunotherapies seem to be less effective than might be expected from preclinical studies, to which a highly immunosuppressive tumor microenvironment significantly contributes [4].

The ability to escape immunosurveillance is considered an emerging hallmark of cancer [5]. Interleukins (IL)-4 and IL-13 are among the immunomodulatory cytokines believed to play a prominent role in tumor immunity [4]. They might be secreted by tumor-supporting cells and aid tumor growth by inducing and activating immunosuppressive phenotypes in surrounding immune cells $[4,6]$. Moreover, a growing body of evidence shows that, if relevant receptors are expressed, they might promote tumor growth also directly, by inducing cancer cell proliferation and migration and/or by protecting transformed cells from apoptosis. Immune cells express receptors consisting of IL-4R $\alpha$ and common $\gamma c$ subunits (type I IL-4 receptor). The receptor on epithelial cancer cells, referred to as type II IL-4 receptor, consist of IL-4R $\alpha$ and IL-13R $\alpha 1$. IL-13 may interact with type II IL-4R or bind to its specific IL-13R $\alpha 2$ receptor $[7,8]$. However, IL-13R $\alpha 2$ has been considered a decoy receptor unable to transduce signal because of the lack of significant cytoplasmic domain [9]. Still, others have proven its relevance for cancer invasion and metastasis $[10,11]$.

The expression of both interleukins and their receptors in various tumors is increasingly being demonstrated (reviewed in [7,8]). Moreover, possible autocrine mode of action has been investigated [12]. However, available literature data concerning IL-4 and IL-13 in CRC and upper GIT cancers are fragmentary and frequently inconsistent. Contradicting findings have been reported, especially concerning the interleukins' status at local and systemic level and their association with the disease advancement [13-15]. Consequently, both tumor promoting [10,16-22] and protective roles $[14,15,23-30]$ have been advocated for IL-4 and IL-13. In the light of existing controversies, the aim of present study is a comprehensive comparative analysis of IL-4 and IL-13 expression at mRNA and protein level, local and systemic, in CRC as compared to esophageal and gastric cancers. Interleukin quantification was accompanied by transcriptional analysis of expression patterns of type II IL-4 receptor subunits (IL-4R $\alpha$ and IL-13R $\alpha 1$ ). In addition, clinical samples were screened for potential associations with representative indicators of: angiogenesis (hypoxia-inducible factor $1 \alpha$ (HIF1A) and vascular endothelial growth factor A (VEGFA)); apoptosis (BCL2, BCLxL, and p21 CIP1/WAF1 (CDKN1A)); proliferation (Ki67); inflammation (CCL2, cyclooxygenase-2 (PTGS2), and inducible nitric oxide synthase (NOS2)); metabolic reprogramming (glucose transporter (GLUT1), ornithine decarboxylase from nitric oxide/polyamine pathway (ODC1), and NOS2) and epithelial-mesenchymal transition (EMT) (smooth muscle $\alpha-2$ actin (ACTA2)) as well as with tight junction proteins (zonula occludens-1 (TJP1) and claudin-2 (CLDN2)). The possibility of cause-effect relationship in CRC as well as the interleukin effect on cell viability and motility is then explored in vitro.

\section{Results}

\subsection{Local Expression of Interleukins and Their Receptors}

IL-4 and IL-13 protein expression was determined in tissue homogenates using dedicated immunoassays and expressed per gram of tissue, while IL4/IL13 and IL4Ra/IL13Ra1 transcripts were quantified using reversely transcribed real time (quantitative) PCR methodology and SYBR green chemistry, as described in detail in Materials and Methods section.

\subsubsection{Characteristics of Study Population}

Patients'-matched samples of tumor and tumor-adjacent macroscopically normal tissue were collected intraoperatively from patients with CRC, ESCC, or GC for mRNA $(n=51)$ and protein analysis $(n=49)$. Patients in each cancer group were matched regarding age, sex distribution, and the disease advancement (Tables 1 and 2). 
Table 1. Characteristics of study population for analysis of local interleukin expression at mRNA level.

\begin{tabular}{ccccc}
\hline Characteristics & ESCC & GC & CRC & $p$ \\
\hline$n$ & 16 & 14 & 21 & - \\
Sex (F/M), $n$ & $6 / 10$ & $3 / 11$ & $7 / 14$ & $0.619^{1}$ \\
Age [yrs.], mean \pm SD & $63.3 \pm 7$ & $67.3 \pm 10$ & $67.7 \pm 11.4$ & $0.431^{2}$ \\
Stage (I/II/III/IV) & $0 / 5 / 10 / 1$ & $3 / 3 / 5 / 3$ & $5 / 9 / 7 / 0$ & $0.064^{1}$ \\
Primary tumor, T (1/2/3/4) & $0 / 5 / 8 / 3$ & $2 / 2 / 8 / 2$ & $1 / 5 / 15 / 0$ & $0.241^{1}$ \\
Lymph node metastasis, N (no/yes) & $8 / 8$ & $6 / 8$ & $14 / 7$ & $0.261^{1}$ \\
Distant metastasis, M (no/yes) & $15 / 1$ & $11 / 3$ & $21 / 0$ & $0.067^{1}$ \\
\hline
\end{tabular}

n, number of observations; F/M, female-to-male ratio; yrs., years; SD, standard deviation; ${ }^{1}$, Chi-squared test; ${ }^{2}$, one-way ANOVA; ESCC, esophageal squamous cell carcinoma; GC, gastric adenocarcinoma; CRC, colorectal adenocarcinoma.

Table 2. Characteristics of study population for analysis of local interleukin expression at protein level.

\begin{tabular}{ccccc}
\hline Characteristics & ESCC & GC & CRC & $p$ \\
\hline$n$ & 18 & 14 & 17 & - \\
Sex (F/M), $n$ & $8 / 10$ & $3 / 11$ & $7 / 10$ & $0.365^{1}$ \\
Age [yrs.], mean \pm SD & $64.1 \pm 5.6$ & $67.3 \pm 10$ & $66.8 \pm 11.3$ & $0.567^{2}$ \\
Stage (I/II/II//V) & $2 / 6 / 9 / 1$ & $3 / 3 / 5 / 3$ & $4 / 8 / 5 / 0$ & $0.248^{1}$ \\
Primary tumor, T (1/2/3/4) & $1 / 6 / 9 / 2$ & $2 / 1 / 9 / 2$ & $1 / 5 / 11 / 0$ & $0.424^{1}$ \\
Lymph node metastasis, N (no/yes) & $9 / 9$ & $6 / 8$ & $12 / 5$ & $0.261^{1}$ \\
Distant metastasis, M (no/yes) & $17 / 1$ & $11 / 3$ & $17 / 0$ & $0.084^{1}$ \\
\hline
\end{tabular}

$n$, number of observations; $\mathrm{F} / \mathrm{M}$, female-to-male ratio; yrs., years; $\mathrm{SD}$, standard deviation; ${ }^{1}$, Chi-squared test; ${ }^{2}$, one-way ANOVA; ESCC, esophageal squamous cell carcinoma; GC, gastric adenocarcinoma; CRC, colorectal adenocarcinoma.

2.1.2. Concentration of IL-4 Protein and Expression of IL4 and IL4Ra Transcripts in CRC as Compared to Upper GIT Cancers

Paired comparison of IL-4 in adjacent and tumor colonic tissue showed significantly higher protein concentration in tumors but similar expression level of IL4 and IL4Ra transcripts (Figure 1).

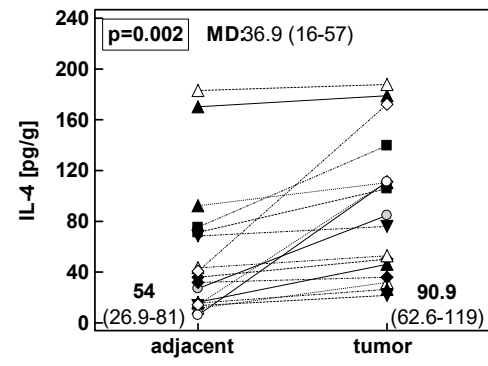

(a)

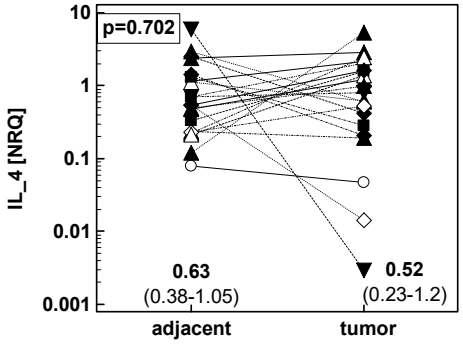

(b)

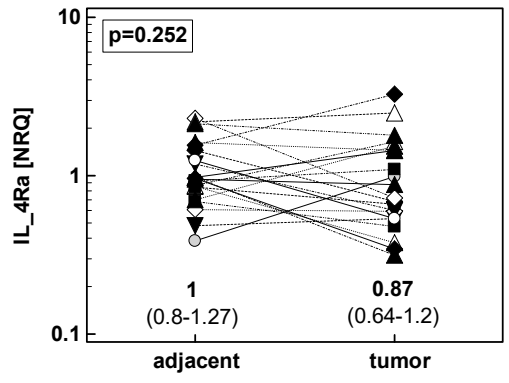

(c)

Figure 1. Patients'-matched analysis of tumor and tumor-adjacent tissue expression of: (a) IL-4 protein in CRC ( $n=17)$; (b) IL4 mRNA in CRC $(n=21)$; (c) IL4Ra mRNA in CRC $(n=21)$. Data were analyzed as logs using $t$-test for paired samples and presented as geometric means with $95 \%$ confidence interval (CI). Mean difference in protein concentration (MD) between groups is accompanied by $95 \%$ CI. Transcriptomic data are presented as normalized relative quantities (NRQ). CRC, colorectal cancer; ESCC, esophageal squamous cell carcinoma; GC, gastric adenocarcinoma.

Similar to CRC, patients with GC or ESCC had significantly higher IL-4 protein concentration in tumors. The differences in IL4 and IL4Ra transcripts between adjacent and tumor tissue were non-significant (Figure 2). 


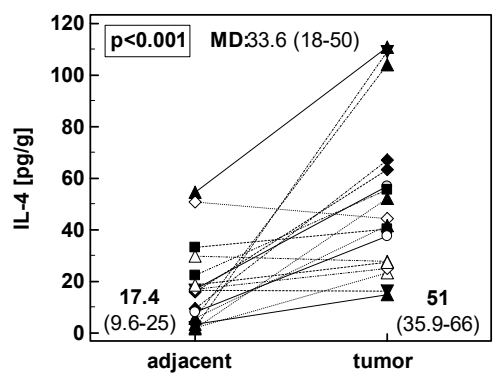

(a)

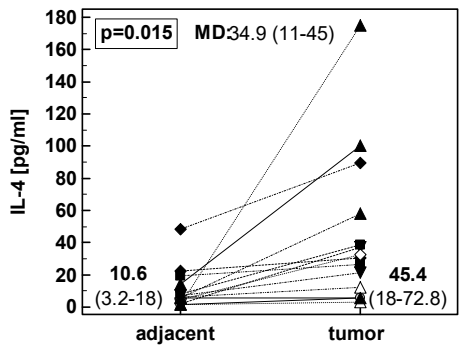

(d)

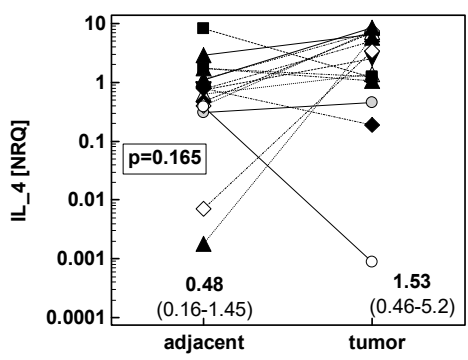

(b)

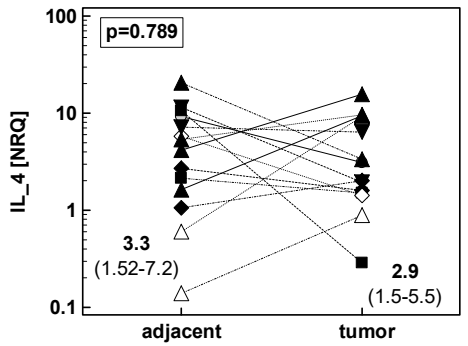

(e)

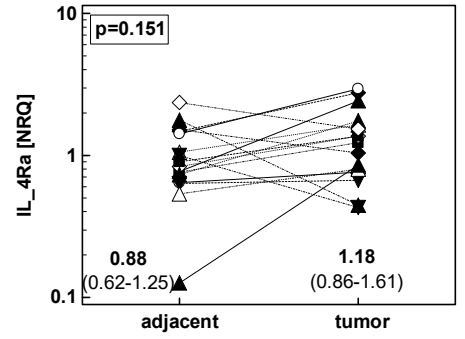

(c)

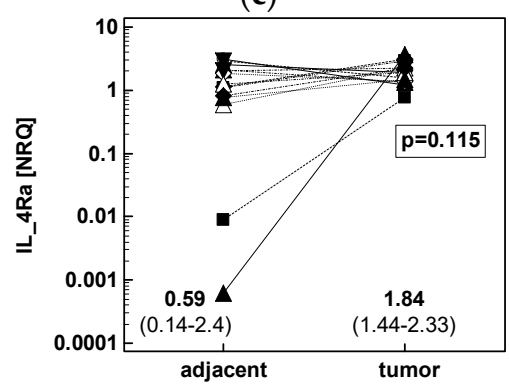

(f)

Figure 2. Patients'-matched analysis of tumor and tumor-adjacent tissue expression of: (a) IL-4 protein in ESCC ( $n=18)$; (b) IL4 mRNA in ESCC ( $n=16)$; (c) IL4Ra mRNA in ESCC $(n=16)$; (d) IL-4 protein in GC $(n=14)$; (e) IL4 mRNA in GC $(n=14)$; (f) IL4Ra mRNA in GC $(n=14)$. Data were analyzed as logs using $t$-test for paired samples and presented as geometric means with $95 \%$ confidence interval (CI). Mean difference in protein concentration (MD) between groups is accompanied by $95 \%$ CI. Transcriptomic data are presented as normalized relative quantities (NRQ). CRC, colorectal cancer; ESCC, esophageal squamous cell carcinoma; GC, gastric adenocarcinoma.

The level of IL-4 protein upregulation in tumor tissue was comparable between anatomical sites, whether expressed as mean difference (MD) or fold-change (tumor-to-adjacent ratio) (Figure 3). Fold-change in IL4 transcripts was comparable in CRC and upper GIT cancers as well. In turn, IL4Ra was more markedly upregulated in tumors from GC than CRC patients, despite high dispersion of values around mean in GC (Figure 3).

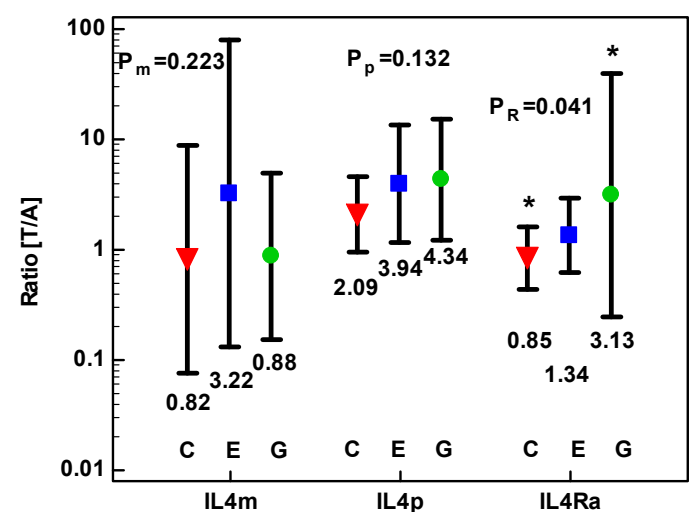

Figure 3. Effect of anatomical site on fold-change in IL4 mRNA (IL4m), IL-4 protein (IL4p), and IL4Ra expression in tumor as compared to adjacent tissue [T/A]. Data were analyzed as logs using one-way ANOVA and presented as geometric means with 95\% confidence interval (whiskers). Red triangles represent mean values in colorectal cancers (denoted as C); blue squares represent mean values in esophageal squamous cell carcinoma (denoted as E); green circles represent mean values in gastric adenocarcinoma (denoted as $G$ ). $p$ values for IL4 mRNA analysis are denoted as $P_{m}$, for IL-4 protein analysis as $\mathrm{P}_{\mathrm{p}}$, and for IL4Ra mRNA analysis as $\mathrm{P}_{\mathrm{R}}$. Statistically significant between-group differences are marked with asterisks $\left({ }^{*}\right)$. 
However, there were significant differences between cancer types in IL-4 protein and IL4 and IL4R $a$ transcript numbers, in both tumor and adjacent tissue, when they were analyzed directly and not as a fold-change. The absolute IL-4 protein concentration in adjacent tissue was significantly higher in colonic than gastric tissue. In tumors, it was higher in colonic as compared to both gastric and esophageal tumors (Figure 4a). Contrary to IL-4 protein, IL4 mRNA expression in non-cancerous tissue was the highest in GC. It was also higher in GC as compared to CRC tumors (Figure $4 b$ ). The expression of IL4Ra mRNA differed significantly between anatomical sites only for tumor tissue, with IL4Ra expression significantly higher in GC as compared to CRC and ESCC tumors (Figure 4c).

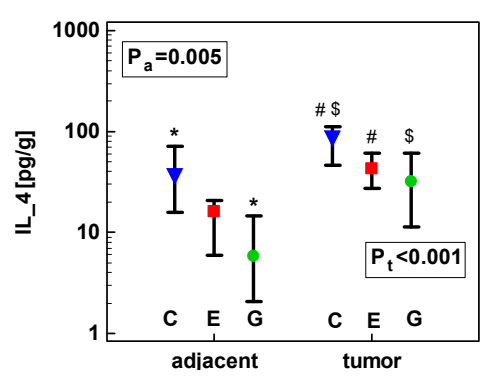

(a)

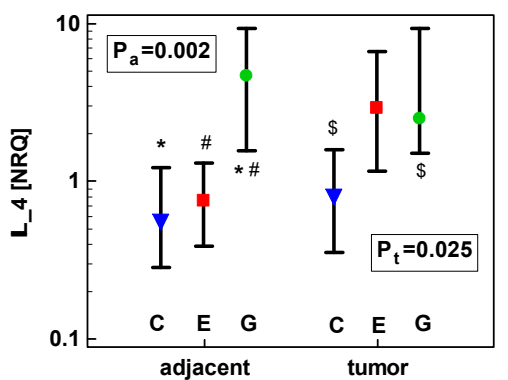

(b)

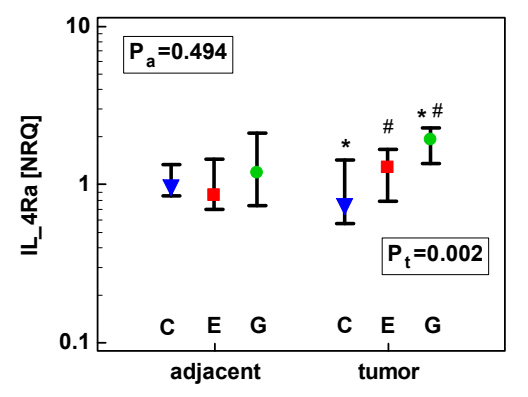

(c)

Figure 4. Effect of anatomical site on tumor and tumor-adjacent tissue expression of: (a) IL-4 protein; (b) IL4 mRNA; (c) IL4Ra mRNA. Data analyzed as logs using one-way ANOVA and presented as geometric means with $95 \%$ confidence interval (whiskers). Blue triangles represent mean values in colorectal cancers (denoted as C); red squares represent mean values in esophageal squamous cell carcinoma (denoted as E); green circles represent mean values in gastric adenocarcinoma (denoted as G). $p$ values for the analysis in adjacent tissue are denoted as $P_{a}$ and for tumor tissue as $P_{t}$. Statistically significant differences between groups are marked with symbols of the same type $\left(^{*}, \#\right.$, etc.). Transcriptomic data presented as normalized relative quantities (NRQ).

Fold-change in IL-4 protein concentration in CRC was not related to any evaluated pathological data. In ESCC, fold-increase in IL-4 protein concentration in tumor was strongly directly correlated with tumor grade. In GC, it was significantly higher in M1 cancers and tended to correlate positively with cancer stage (Table 3).

Table 3. Association of demographic and pathological data with IL-4 protein concentration in the GIT cancer patients.

\begin{tabular}{cccc}
\hline \multirow{2}{*}{ Data } & \multicolumn{2}{c}{ Fold-Change [Tumor-to-Adjacent] in IL-4 Protein Concentration } \\
\cline { 2 - 4 } & CRC & ESCC & GC \\
\hline Age & $\mathrm{r}=0, p=0.897^{1}$ & $\mathrm{r}=0, p=0.930^{1}$ & $\mathrm{r}=0.46, p=0.099^{1}$ \\
Sex F vs. M & 1.6 vs. $4.2, p=0.199^{2}$ & 7.9 vs. $9.2, p=0.844^{2}$ & 10.1 vs. $3.1, p=0.392^{3}$ \\
TNM & $\rho=0.11, p=0.679^{4}$ & $\rho=0.15, p=0.553^{4}$ & $\rho=0.53, p=0.051^{4}$ \\
T & $\rho=0.20, p=0.452^{4}$ & $\rho=0.08, p=0.762^{4}$ & $\rho=0.46, p=0.100^{4}$ \\
N0 vs. N $\geq 1$ & 3.5 vs. $2.2, p=0.568^{2}$ & 6.6 vs. 10.7, $p=0.528^{2}$ & 3.7 vs. 19.6, $p=0.349^{2}$ \\
M0 vs. M1 & - & - & 2.1 vs. $17.6, p=0.024^{3}$ \\
G & $\rho=0.36, p=0.161^{4}$ & $\rho=0.73, p<0.001^{4}$ & $\rho=0.32, p=0.271^{4}$ \\
\hline
\end{tabular}

\footnotetext{
${ }^{1}$ Data analyzed with Pearson correlation test $(r) ;{ }^{2}$ analyzed with $t$-test for independent samples; ${ }^{3}$ analyzed with Mann-Whitney U test; ${ }^{4}$ analyzed with Spearman rank correlation $(\rho)$. GIT, gastrointestinal tract; CRC, colorectal adenocarcinoma; ESCC, squamous cell carcinoma of esophagus; GC, gastric adenocarcinoma; F, females; M, males; TNM, tumor-node-metastasis grading system; $\mathrm{T}$, depth of invasion (primary tumor extension); $\mathrm{N}$, lymph node metastasis; $\mathrm{M}$, distant metastasis; $\mathrm{G}$, grade.
}

Interestingly, positive correlation between tumor grade and fold-change in IL-4 protein concentration in ESCC patients resulted from a negative correlation observed in adjacent non-cancerous tissue ( $\rho=-0.60, p=0.009)$ and not from an increasing IL-4 accumulation in tumor. Similarly, there was 
an inverse relationship between tumor grade and IL-4 protein concentration in non-cancerous tissue in CRC ( $\rho=-0.55, p=0.021)$. Those results might imply decreasing number of IL-4 secreting cells in tumor surrounding tissue with increasing cancer aggressiveness.

Fold-change in IL4 transcript number was significantly lower in ESCC patients with lymph node metastasis. In addition, it tended to be inversely related with tumor extension in CRC (Table 4). In GC, IL4 transcript number in tumor tissue tended to positively correlate with TNM stage $(\rho=0.48, p=0.082)$ and to be higher in tumors from patients with lymph node metastasis (4.5 vs. 1.6, $p=0.091)$.

Table 4. Association of demographic and pathological data with IL4 mRNA expression in the GIT cancer patients.

\begin{tabular}{cccc}
\hline \multirow{2}{*}{ Data } & \multicolumn{2}{c}{ Fold-Change [Tumor-to-Adjacent] in IL4 Transcript Number } \\
\cline { 2 - 4 } & CRC & ESCC & GC \\
Age & $\mathrm{r}=16, p=0.475^{1}$ & $\mathrm{r}=21, p=0.444^{1}$ & $\mathrm{r}=-0.22, p=0.440^{1}$ \\
Sex F vs. M & 1.7 vs. $0.6, p=0.331^{2}$ & 12.2 vs. $1.4, p=0.206^{2}$ & 0.3 vs. $1.2, p=0.172^{2}$ \\
TNM & $\rho=-0.14, p=0.548^{3}$ & $\rho=-0.21, p=0.427^{3}$ & $\rho=0.06, p=0.834^{3}$ \\
T & $\rho=-0.37, p=0.096^{3}$ & $\rho=-0.17, p=0.529^{3}$ & $\rho=-0.06, p=0.829^{3}$ \\
N0 vs. N $\geq 1$ & 0.7 vs. $1.3, p=0.549^{2}$ & 17.4 vs. $0.6, p=0.030^{2}$ & 0.6 vs. $1.2, p=0.490^{2}$ \\
M0 vs. M1 & - & - & 1.0 vs. $0.7, p=0.747^{2}$ \\
G & $\rho=0.01, p=0.796^{3}$ & $\rho=0.08, p=0.759^{3}$ & $\rho=0, p=0.973^{3}$ \\
\hline
\end{tabular}

${ }^{1}$ Data analyzed with Pearson correlation test $(r) ;{ }^{2}$ analyzed with $t$-test for independent samples; ${ }^{3}$ analyzed with Spearman rank correlation $(\rho)$. GIT, gastrointestinal tract; CRC, colorectal adenocarcinoma; ESCC, squamous cell carcinoma of esophagus; GC, gastric adenocarcinoma; F, females; M, males; TNM, tumor-node-metastasis grading system; T, depth of invasion (primary tumor extension); N, lymph node metastasis; M, distant metastasis; G, grade.

There was no significant association between fold change in expression level of $\operatorname{IL} 4 R a$ and pathological data in any cancer type. Only $I L 4 R a$ fold-change tended to be lower in ESCC patients with lymph node metastasis (Table 5).

Table 5. Association of demographic and pathological data with IL4Ra mRNA expression in the GIT cancer patients.

\begin{tabular}{cccc}
\hline \multirow{2}{*}{ Data } & \multicolumn{2}{c}{ Fold-Change [Tumor-to-Adjacent] in IL4R $a$ Transcript Number } \\
\cline { 2 - 4 } & CRC & ESCC & GC \\
Age & $\mathrm{r}=22, p=0.347^{1}$ & $\mathrm{r}=25, p=0.355^{1}$ & $\mathrm{r}=0, p=0.999^{1}$ \\
Sex F vs. M & 1.1 vs. $0.7, p=0.191^{2}$ & 1 vs. $1.6, p=0.255^{2}$ & 4 vs. $2.9, p=0.854^{2}$ \\
TNM & $\rho=-0.05, p=0.815^{3}$ & $\rho=0.06, p=0.839^{3}$ & $\rho=-0.25, p=0.383^{3}$ \\
T & $\rho=-0.07, p=0.772^{3}$ & $\rho=0.13, p=0.627^{3}$ & $\rho=-0.25, p=0.390^{3}$ \\
N0 vs. N $\geq 1$ & 0.9 vs. $0.8, p=0.729^{2}$ & 1.9 vs. $1, p=0.074^{2}$ & 3 vs. $3.2, p=0.958^{2}$ \\
M0 vs. M1 & - & - & 4.1 vs. $0.2, p=0.492^{2}$ \\
G & $\rho=-0.04, p=0.863^{3}$ & $\rho=0.47, p=0.077^{3}$ & $\rho=0.05, p=0.861^{3}$ \\
\hline
\end{tabular}

\footnotetext{
${ }^{1}$ Data analyzed with Pearson correlation test $(r) ;{ }^{2}$ analyzed with $t$-test for independent samples; ${ }^{3}$ analyzed with Spearman rank correlation $(\rho)$. GIT, gastrointestinal tract; CRC, colorectal adenocarcinoma; ESCC, squamous cell carcinoma of esophagus; GC, gastric adenocarcinoma; F, females; M, males; TNM, tumor-node-metastasis grading system; T, depth of invasion (primary tumor extension); N, lymph node metastasis; M, distant metastasis; G, grade.
}

In turn, there was an inverse correlation between IL-4 protein concentration and expression of IL4 transcripts in tumor $(\mathrm{r}=-0.40, p=0.019)$ and tumor-adjacent tissue $(\mathrm{r}=-0.43, p=0.011)$ as well as between their fold-change (tumor-to-adjacent; $\mathrm{r}=-0.42, p=0.015$ ).

\subsubsection{Concentration of IL-13 Protein and Expression of IL13 and IL13Ra1 Transcripts in CRC as Compared to upper GIT Cancers}

Paired comparison of IL-13 in adjacent and tumor colonic tissue showed significantly higher protein concentration and IL13 transcript number in tumors but similar expression level of IL13Ra1 transcripts (Figure 5). 


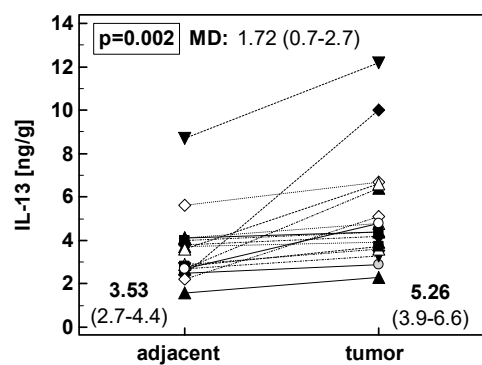

(a)

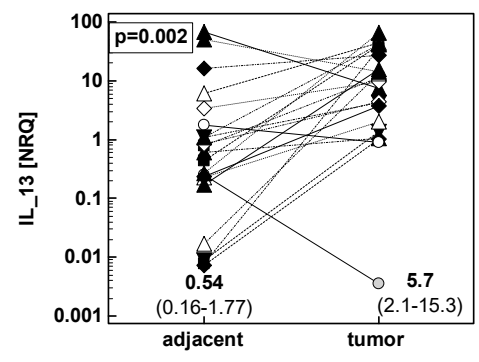

(b)

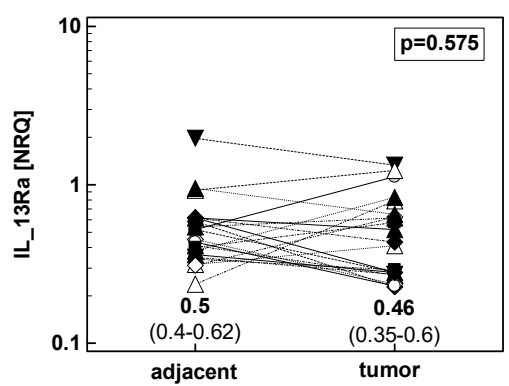

(c)

Figure 5. Patients'-matched analysis of tumor and tumor-adjacent tissue expression of: (a) IL-13 protein in CRC ( $n=17)$; (b) IL13 mRNA in CRC $(n=21)$; (c) IL13Ra1 mRNA in CRC $(n=21)$. Data were analyzed as logs using $t$-test for paired samples and presented as geometric means with $95 \%$ confidence interval (CI). Mean difference in protein concentration (MD) between groups is accompanied by $95 \%$ CI. Transcriptomic data are presented as normalized relative quantities (NRQ). CRC, colorectal cancer; ESCC, esophageal squamous cell carcinoma; GC, gastric adenocarcinoma.

Similarly, patients with GC or ESCC had significantly higher IL-13 protein concentration in tumors but the mean difference in its concentration was lower in CRC than upper GIT cancers (Figure 6). The differences in both IL13 and IL13RaI transcripts between adjacent and tumor tissue were non-significant (Figure 6).

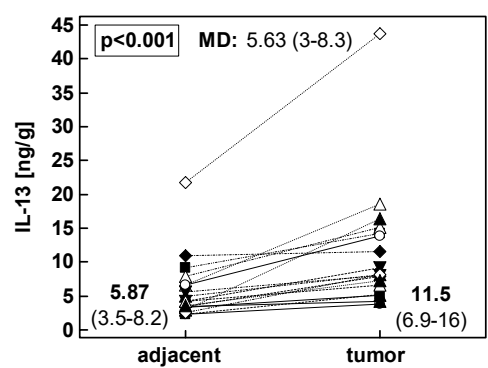

(a)

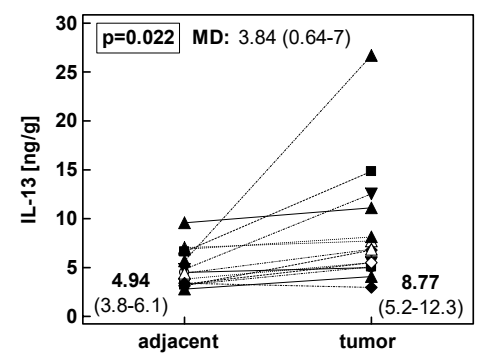

(d)

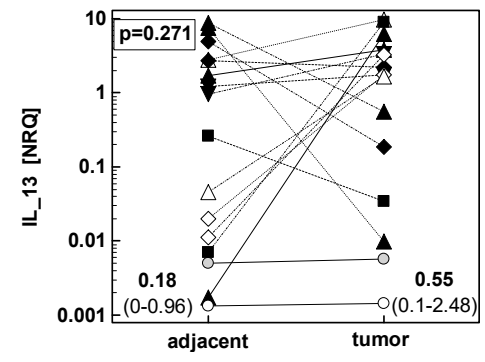

(b)

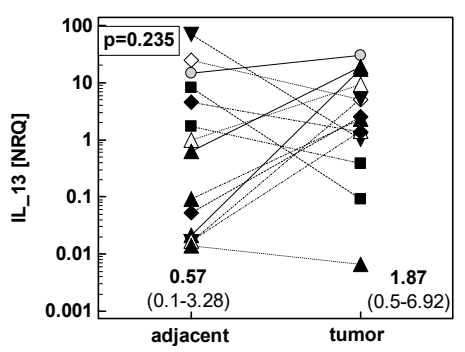

(e)

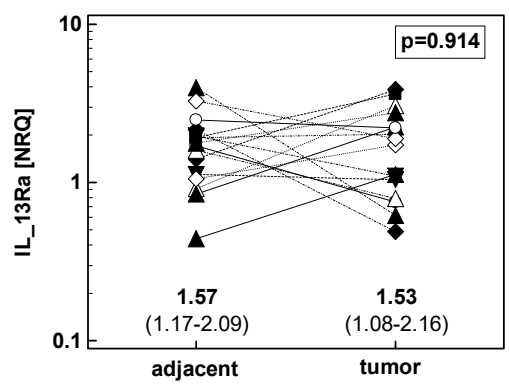

(c)

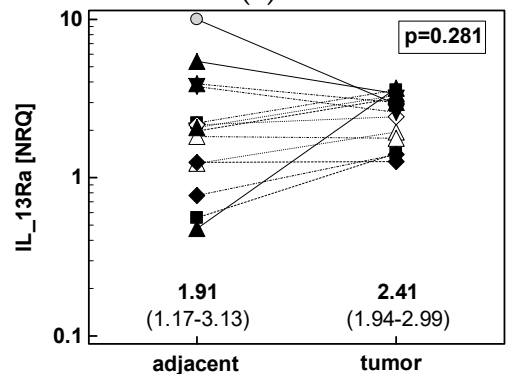

(f)

Figure 6. Patients'-matched analysis of tumor and tumor-adjacent tissue expression of: (a) IL-13 protein in ESCC ( $n=18)$; (b) IL13 mRNA in ESCC $(n=16)$; (c) IL13Ra1 mRNA in ESCC $(n=16)$; (d) IL-13 protein in GC $(n=14)$; (e) IL13 mRNA in GC $(n=14)$; (f) IL13Ra1 mRNA in GC $(n=14)$. Data were analyzed as logs using $t$-test for paired samples and presented as geometric means with $95 \%$ confidence interval (CI). Mean difference in protein concentration (MD) between groups is accompanied by $95 \%$ CI. Transcriptomic data are presented as normalized relative quantities (NRQ). CRC, colorectal cancer; ESCC, esophageal squamous cell carcinoma; GC, gastric adenocarcinoma.

Fold-change in IL-13 protein concentration and expression of IL13 and IL13Ra1 transcripts was comparable in CRC and upper GIT cancers (Figure 7). 


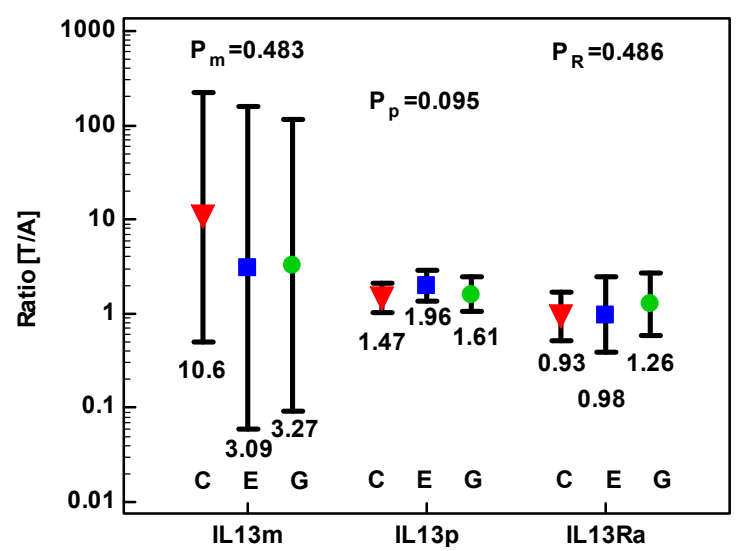

Figure 7. Effect of anatomical site on tumor-to-adjacent expression ratios of IL13 mRNA (IL13m), IL-13 protein (IL13p), and IL13Ra1. Data analyzed as logs using one-way ANOVA and presented as geometric means with $95 \%$ confidence interval (whiskers). Red triangles represent mean values in colorectal cancers (denoted as C); blue squares represent mean values in esophageal squamous cell carcinoma (denoted as E); green circles represent mean values in gastric adenocarcinoma (denoted as $G$ ). $p$ values for IL13 mRNA analysis are denoted as $P_{m}$, for IL-13 protein analysis as $P_{p}$, and for IL13Ra1 mRNA analysis as $P_{R}$.

However, there were significant anatomical site-associated differences in IL-13 protein concentrations (Figure 8a) and IL13Ra1 expression (Figure 8c). In both adjacent and tumor tissue (Figure 8), they were the lowest in CRC patients. In addition, tumor tissue from ESCC patients had significantly lower IL13Ra1 (Figure 8c) and IL13 expression (Figure 8b) as compared to GC patients.

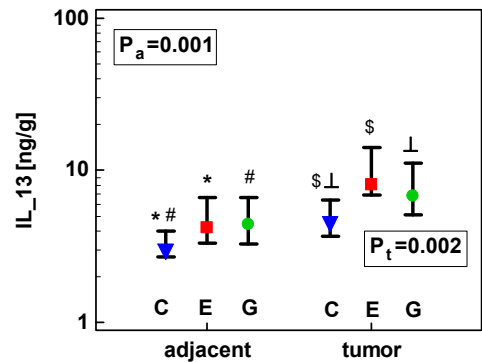

(a)

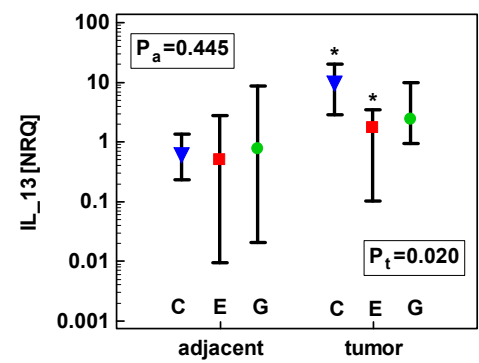

(b)

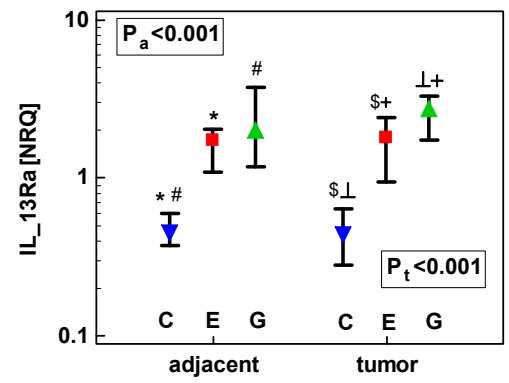

(c)

Figure 8. Effect of anatomical site on tumor and tumor-adjacent tissue expression of: (a) IL-13 protein; (b) IL13 mRNA; (c) IL13Ra1 mRNA. Data analyzed as logs using one-way ANOVA and presented as geometric means with $95 \%$ confidence interval (whiskers). Blue triangles represent mean values in colorectal cancers (denoted as C); red squares represent mean values in esophageal squamous cell carcinoma (denoted as E); green circles represent mean values in gastric adenocarcinoma (denoted as G). $p$ values for the analysis in adjacent tissue are denoted as $P_{a}$ and for tumor tissue as $P_{t}$. Statistically significant differences between groups are marked with symbols of the same type $\left({ }^{*}, \#\right.$, etc.). Transcriptomic data presented as normalized relative quantities (NRQ).

Fold-change in IL-13 protein concentration positively correlated with TNM stage in CRC patients and tended to be higher in N1 patients (Table 6). The association with TNM in CRC resulted from IL-13 decrease along with increasing TNM in adjacent tissue $(\rho=-0.42, p=0.093)$ rather than its increase in tumor $(\rho=0.20, p=0.436)$. No significant association between fold-change in IL-13 protein concentration and cancer pathology was observed in ESCC and GC (Table 6). However, the interleukin concentration changed with TNM and/or T in both cancers. Yet, as the change occurred in both tumor and non-cancerous tissue, it was not reflected by a fold-change. In ESCC, IL-13 protein concentration increased along with advancing TNM in tumor $(\rho=0.56, p=0.016)$ and tumor-adjacent 
tissue $(\rho=0.52, p=0.026)$ and tended to positively correlate with $\mathrm{T}$ in tumors $(\rho=0.43, p=0.078)$. In GC, it was negatively correlated with T, significantly so in adjacent tissue $(\rho=-0.62, p=0.019)$ and non-significantly in tumors $(\rho=-0.45, p=0.104)$. It also tended to correlate with TNM $(\rho=-0.50$, $p=0.072$ in adjacent and $\rho=-0.50, p=0.069$ in tumor tissue). In addition, IL-13 protein concentration was significantly lower in GC patients with lymph node metastasis when evaluated either in tumor (5.5 vs. $11.4, p=0.008$ ) or non-cancerous adjacent tissue (3.9 vs. $5.8, p=0.039$ ).

Table 6. Association of demographic and pathological data with IL-13 protein concentration in the GIT cancer patients.

\begin{tabular}{cccc}
\hline \multirow{2}{*}{ Data } & \multicolumn{2}{c}{ Fold-Change [Tumor-to-Adjacent] in IL-13 Protein Concentration } \\
\cline { 2 - 4 } & CRC & ESCC & GC \\
Age & $\mathrm{r}=23, p=0.366^{1}$ & $\mathrm{r}=-0.19, p=0.449^{1}$ & $\mathrm{r}=0.34, p=0.231^{1}$ \\
Sex F vs. M & 1.4 vs. $1.5, p=0.565^{2}$ & 2 vs. $2.2, p=0.740^{2}$ & 2.2 vs. $1.4, p=0.136^{2}$ \\
TNM & $\rho=0.54, p=0.024^{3}$ & $\rho=-0.02, p=0.940^{3}$ & $\rho=-0.13, p=0.658^{3}$ \\
T & $\rho=0.30, p=0.251^{3}$ & $\rho=0.12, p=0.631^{3}$ & $\rho=0.14, p=0.643^{3}$ \\
N0 vs. N $\geq 1$ & 1.3 vs. $1.9, p=055^{2}$ & 2 vs. $2, p=0.965^{2}$ & 2 vs. $1.4, p=0.155^{2}$ \\
M0 vs. M1 & - & - & 1.9 vs. $1.4, p=0.506^{2}$ \\
G & $\rho=-0.07, p=0.797^{3}$ & $\rho=-0.37, p=0.137^{3}$ & $\rho=0.15, p=0.601^{3}$ \\
\hline
\end{tabular}

${ }^{1}$ Data analyzed with Pearson correlation test $(r) ;^{2}$ analyzed with $t$-test for independent samples; ${ }^{3}$ analyzed with
Spearman rank correlation ( $\rho$ ). GIT, gastrointestinal tract; CRC, colorectal adenocarcinoma; ESCC, squamous cell
carcinoma of esophagus; GC, gastric adenocarcinoma; F, females; M, males; TNM, tumor-node-metastasis grading
system; T, depth of invasion (primary tumor extension); N, lymph node metastasis; M, distant metastasis; G, grade.

Fold-change in IL13 expression was significantly lower in CRC patients with lymph node metastasis and inversely related to the TNM stage (Table 7). The inverse association with lymph node involvement was a result of higher IL13 transcript expression in tumor-adjacent non-cancerous tissue in N1 than N0 CRC patients ( 3 vs. $0.2, p=0.028$ ) and a tendency toward its lower expression in tumors from N1 patients (2.2 vs. 9.2, $p=0.158$ ). Similarly, IL13 expression in non-cancerous adjacent tissue tended to correlate positively with TNM $(\rho=0.42, p=0.059)$.

Table 7. Association of demographic and pathological data with IL13 expression in the GIT cancer patients.

\begin{tabular}{cccc}
\hline \multirow{2}{*}{ Data } & \multicolumn{2}{c}{ Fold-Change [Tumor-to-Adjacent] in IL13 Expression } \\
\cline { 2 - 4 } & CRC & ESCC & GC \\
Age & $\mathrm{r}=25, p=0.266^{1}$ & $\mathrm{r}=-0.24, p=0.367^{1}$ & $\mathrm{r}=0.1, p=0.736^{1}$ \\
Sex F vs. M & 14.8 vs. $9, p=0.736^{2}$ & 1.2 vs. $5.4, p=0.483^{2}$ & 0.2 vs. $6.8, p=0.145^{2}$ \\
TNM & $\rho=-0.56, p=0.009^{3}$ & $\rho=-0.34, p=0.192^{3}$ & $\rho=0.13, p=0.647^{3}$ \\
T & $\rho=-0.16, p=0.490^{3}$ & $\rho=-0.24, p=0.381^{3}$ & $\rho=-0.27, p=0.344^{3}$ \\
N0 vs. N $\geq 1$ & 40.7 vs. $0.7, p=002^{2}$ & 4.9 vs. $1.9, p=0.650^{2}$ & 1.5 vs. $6, p=0.485^{2}$ \\
M0 vs. M1 & - & - & 2.2 vs. $13.5, p=0.460^{2}$ \\
G & $\rho=-0.04, p=0.863^{3}$ & $\rho=0.01, p=0.968^{3}$ & $\rho=-0.24, p=0.417^{3}$ \\
\hline
\end{tabular}

${ }^{1}$ Data analyzed with Pearson correlation test $(r) ;{ }^{2}$ analyzed with $t$-test for independent samples; ${ }^{3}$ analyzed with Spearman rank correlation $(\rho)$. GIT, gastrointestinal tract; CRC, colorectal adenocarcinoma; ESCC, squamous cell carcinoma of esophagus; GC, gastric adenocarcinoma; F, females; M, males; TNM, tumor-node-metastasis grading system; T, depth of invasion (primary tumor extension); N, lymph node metastasis; $M$, distant metastasis; $\mathrm{G}$, grade.

There were no significant associations between IL13Ra1 expression and pathology in any of the examined cancers (Table 8). Likewise, receptor expression did not correlate with pathological findings in tumor and adjacent tissues. 
Table 8. Association of demographic and pathological data with IL13Ra1 expression in the GIT cancer patients.

\begin{tabular}{cccc}
\hline \multirow{2}{*}{ Data } & \multicolumn{2}{c}{ Fold-Change [Tumor-to-Adjacent] in IL13Ra1 Expression } \\
\cline { 2 - 4 } & CRC & ESCC & GC \\
\hline Age & $\mathrm{r}=19, p=0.406^{1}$ & $\mathrm{r}=-0.21, p=0.436^{1}$ & $\mathrm{r}=-0.23, p=0.434^{1}$ \\
Sex F vs. M & 0.8 vs. $1, p=0.570^{2}$ & 0.9 vs. $1.1, p=0.658^{2}$ & 1.1 vs. $1.3, p=0.670^{2}$ \\
TNM & $\rho=0.03, p=0.910^{3}$ & $\rho=0.05, p=0.844^{3}$ & $\rho=-0.08, p=0.774^{3}$ \\
T & $\rho=-0.08, p=0.723^{3}$ & $\rho=0.18, p=0.517^{3}$ & $\rho=0.14, p=0.641^{3}$ \\
N0 vs. N $\geq 1$ & 0.9 vs. $1, p=749^{2}$ & 1.4 vs. $0.7, p=0.144^{2}$ & 1.1 vs. $1.4, p=0.618^{2}$ \\
M0 vs. M1 & - & - & 1.3 vs. $1, p=0.547^{2}$ \\
G & $\rho=0, p=1^{3}$ & $\rho=0.03, p=0.903^{3}$ & $\rho=0.20, p=0.490^{3}$ \\
\hline
\end{tabular}

${ }^{1}$ Data analyzed with Pearson correlation test $(r) ;{ }^{2}$ analyzed with $t$-test for independent samples; ${ }^{3}$ analyzed with Spearman rank correlation $(\rho)$. GIT, gastrointestinal tract; CRC, colorectal adenocarcinoma; ESCC, squamous cell carcinoma of esophagus; GC, gastric adenocarcinoma; $\mathrm{F}$, females; $\mathrm{M}$, males; TNM, tumor-node-metastasis grading system; T, depth of invasion (primary tumor extension); $\mathrm{N}$, lymph node metastasis; $\mathrm{M}$, distant metastasis; $\mathrm{G}$, grade.

There was no correlation between IL-13 protein concentration and IL13 transcript number in tumor or adjacent tissue and neither was the fold-change correlated. Similarly, there was no significant correlation between transcript numbers of IL13 and IL13RaI or between IL-13 protein concentration and IL13Ra1.

2.1.4. Correlation Pattern between IL4, IL4Ra, IL13, and IL13Ra1 and the Expression of Mediators Relevant for Cancer Growth in CRC Patients

Transcriptional analysis of correlation patterns was conducted on clinical samples from CRC patients to reveal possible association between expression level of IL4, IL4Ra, IL13, and IL13RaI and that of representative mediators/markers associated with cancer development and progression. We investigated mediators of angiogenesis (hypoxia inducible factor $1 \alpha$ (HIF1A) and vascular endothelial growth factor A (VEGFA)), apoptosis (antiapoptotic BCL2 and BCLxL and cell cycle regulator p21 ${ }^{\mathrm{CIP1}} / \mathrm{WAF1}(C D K N 1 A)$ ), proliferation (Ki67), inflammation (monocyte chemoattractant protein 1 (CCL2), cyclooxygenase-2 (PTGS2) and inducible nitric oxide synthase (NOS2)), metabolic reprogramming (glucose transporter 1(GLUT1), ornithine decarboxylase (ODC1) and NOS2), EMT (smooth muscle $\alpha-2$ actin (ACTA2)), and tight junction proteins (zonula occludens-1 (TJP1) and claudin-2 (CLDN2)).

Fold-change in expression ratio of IL13Ra1 positively correlated with fold-change in CDKN1A and VEGFA and tended to correlate with HIF1A, while IL13 displayed no significant correlations. Fold-change in expression ratio of IL4Ra positively correlated with fold-change in ACTA2, CCL2, CDKN1A, PTGS2, TJP1, and VEGFA and tended to positively correlate with HIF1A but was inversely related to CLDN2 and Ki67. Fold-change in IL4 tended to be positively correlated with fold-change in ACTA2 (Table 9).

The correlation analysis of gene expression in tumor tissue showed IL13Ra1 to correlate positively with ACTA2, CCL2, CDKN1A, HIF1A, TJP1, and VEGFA and tended to correlate with BCL2 while IL13 tended to correlate positively with PTGS2 and VEGFA. Expression of IL4Ra in CRC tumors correlated positively with ACTA2, BCL2, CCL2, CDKN1A, HIF1A, TJP1, and VEGFA and tended to correlate positively with $B C L x L$ and negatively with $C L D N 2$ and NOS2, while IL4 tended to correlate negatively with NOS2 (Table 10).

The correlation analysis of gene expression in non-cancerous tumor-adjacent tissue showed fewer correlations. IL13Ra1 expression correlated positively with that of TJP1 and tended to correlate with NOS2 and VEGFA while IL13 expression correlated positively with PTGS2 and tended to correlate negatively with BCL2, GLUT1, and NOS2. IL4Ra expression correlated positively with ACTA2 and PTGS2 and tended to correlate positively with TJP1 but was correlated negatively with Ki67. 
IL4 expression correlated positively with CCL2 and tended to correlate positively with HIF1A and PTGS2 (Table 10).

Table 9. Correlation pattern between fold-change in expression (tumor-to adjacent) of IL4, IL4Ra, IL13, and IL13Ra1 and expression of representative mediators relevant for cancer growth in CRC patients.

\begin{tabular}{ccccc}
\hline Fold-Change in Expression & IL13 & IL13R $\boldsymbol{a} \mathbf{I}$ & $\boldsymbol{I L 4}$ & $\boldsymbol{I L 4 R \boldsymbol { a }}$ \\
\hline ACTA2 & $\mathrm{ns}$ & $\mathrm{ns}$ & 0.394 & $0.57^{2}$ \\
BCLxL & $\mathrm{ns}$ & $\mathrm{ns}$ & $\mathrm{ns}$ & $\mathrm{ns}$ \\
BCL2 & $\mathrm{ns}$ & $\mathrm{ns}$ & $\mathrm{ns}$ & $\mathrm{ns}$ \\
CCL2 & $\mathrm{ns}$ & $\mathrm{ns}$ & $\mathrm{ns}$ & $0.67^{3}$ \\
CDKN1A & $\mathrm{ns}$ & $0.60^{2}$ & $\mathrm{~ns}$ & $0.48^{1}$ \\
CLDN2 & $\mathrm{ns}$ & $\mathrm{ns}$ & $\mathrm{ns}$ & $-0.44^{1}$ \\
GLUT1 & $\mathrm{ns}$ & $\mathrm{ns}$ & $\mathrm{ns}$ & $\mathrm{ns}$ \\
HIF1A & $\mathrm{ns}$ & $\mathrm{ns}$ & $\mathrm{ns}$ & $0.42^{4}$ \\
Ki67 & $\mathrm{ns}$ & $\mathrm{ns}$ & $\mathrm{ns}$ & $-0.48^{1}$ \\
NOS2 & $\mathrm{ns}$ & $\mathrm{ns}$ & $\mathrm{ns}$ \\
ODC1 & $\mathrm{ns}$ & $\mathrm{ns}$ & $\mathrm{ns}$ & $\mathrm{ns}$ \\
PTGS2 & $\mathrm{ns}$ & $\mathrm{ns}$ & $\mathrm{ns}$ & $0.50^{1}$ \\
TJP1 & $\mathrm{ns}$ & $\mathrm{ns}$ & $\mathrm{ns}$ & $0.68^{3}$ \\
VEGFA & $\mathrm{ns}$ & $\mathrm{ns}$ & $0.48^{1}$ \\
\hline
\end{tabular}

Data presented as Spearman correlation coefficients $(\rho){ }^{1}, p<0.05 ;{ }^{2}, p<0.01{ }^{3}, p<0.001 ;{ }^{4}$, tendency $(0.1>p>$ $0.05) ;$ ns, not significant.

Table 10. Correlation pattern between expression of IL4, IL4Ra, IL13, and IL13Ra1 and expression of representative mediators relevant for cancer growth in tumor and tumor-adjacent non-cancerous tissue from CRC patients.

\begin{tabular}{|c|c|c|c|c|c|c|c|c|}
\hline Expression & \multicolumn{4}{|c|}{ Tumor Tissue } & \multicolumn{4}{|c|}{ Adjacent non-Cancerous Tissue } \\
\hline ACTA2 & ns & $0.47^{1}$ & ns & $0.64^{2}$ & ns & ns & ns & $0.58^{2}$ \\
\hline$B C L x L$ & ns & ns & ns & $0.40^{4}$ & ns & ns & ns & ns \\
\hline BCL2 & ns & $0.43^{4}$ & ns & $0.57^{2}$ & $-0.39^{4}$ & ns & ns & ns \\
\hline CCL2 & ns & $0.51^{2}$ & ns & $0.56^{2}$ & ns & ns & $0.47^{1}$ & ns \\
\hline GLUT1 & ns & ns & ns & ns & $-0.41^{4}$ & ns & ns & ns \\
\hline HIF1A & ns & $0.68^{3}$ & ns & $0.51^{1}$ & ns & ns & $0.41^{4}$ & ns \\
\hline Ki67 & ns & ns & ns & ns & ns & $0.42^{4}$ & ns & $-0.46^{1}$ \\
\hline NOS2 & ns & ns & $-0.42^{4}$ & $-0.42^{4}$ & $-0.41^{4}$ & ns & ns & ns \\
\hline ODC1 & ns & ns & ns & ns & ns & ns & ns & ns \\
\hline
\end{tabular}

Data presented as Spearman correlation coefficients $(\rho){ }^{1}, p<0.05 ;^{2}, p<0.01 ;^{3}, p<0.001{ }^{4}$, tendency $(0.1>p>$ $0.05) ;$ ns, not significant.

\subsection{Systemic Concentrations of IL-4 and IL-13 in CRC and upper GIT Cancers}

Systemic concentrations of IL-4 and IL-13 were measured in serum samples using flow cytometry-based Luminex xMAP ${ }^{\circledR}$ technology. Serum samples were collected from 227 cancer patients upon hospital admission prior any treatment and from 36 apparently healthy controls. Data on demography and pathology are summarized in Table 11. 
Table 11. Characteristics of study population for analysis of systemic interleukin concentration.

\begin{tabular}{ccccccc}
\hline Characteristics & CN & ESCC & CC & GC & CRC & $p$ \\
\hline$n$ & 36 & 93 & 32 & 31 & 71 & - \\
Sex (F/M), $n$ & $16 / 20$ & $32 / 61$ & $7 / 25$ & $10 / 21$ & $27 / 44$ & $0.375^{1}$ \\
Age [yrs.], mean \pm SD & $65.4 \pm 8.1$ & $62.4 \pm 8.5$ & $62.3 \pm 8.5$ & $64.1 \pm 9.7$ & $65.8 \pm 10.3$ & $0.110^{2}$ \\
$\quad$ Stage (I/II/III/IV/x) & - & $9 / 21 / 25 / 38$ & $1 / 2 / 4 / 26$ & $1 / 5 / 5 / 20$ & $7 / 28 / 29 / 6 / 1$ & $<0.001^{1}$ \\
$\begin{array}{c}\text { Primary tumor, T } \\
\quad(1 / 2 / 3 / 4 / x)\end{array}$ & - & $11 / 17 / 24 / 41$ & $0 / 1 / 3 / 28$ & $1 / 2 / 9 / 19$ & $1 / 8 / 39 / 22 / 1$ & $<0.001^{1}$ \\
$\begin{array}{c}\text { Lymph node metastasis, } \\
\quad \text { N (no/yes/x) }\end{array}$ & - & $34 / 59$ & $2 / 30$ & $6 / 25$ & $35 / 35 / 1$ & $<0.001^{1}$ \\
$\begin{array}{c}\text { Distant metastasis, M } \\
\text { (no/yes/x) }\end{array}$ & - & $55 / 38$ & $6 / 26$ & $11 / 20$ & $64 / 6 / 1$ & $<0.001^{1}$ \\
\hline
\end{tabular}

n, number of observations; $\mathrm{F} / \mathrm{M}$, female-to-male ratio; yrs., years; $\mathrm{SD}$, standard deviation; $\mathrm{x}$, not determined; ${ }^{1}$, Chi-squared test; ${ }^{2}$, one-way ANOVA; CN, normal controls; ESCC, esophageal squamous cell carcinoma; CC, adenocarcinoma of the gastric cardia; GC, gastric adenocarcinoma; CRC, colorectal adenocarcinoma.

As compared to controls, IL-4 was significantly elevated in all cancers. Patients with adenocarcinomas of gastric cardia (CC) and GC patients had significantly higher IL-4 concentration than ESCC patients and GC patients-significantly higher as compared to CRC patients as well (Figure 9a). There was no correlation between IL-4 and the disease advancement or tumor grade in any of examined cancers.

As compared to controls, IL-13 concentration was significantly higher in ESCC and CRC but lower in GC patients. The ESCC and CRC patients had significantly higher IL-13 concentration also as compared to CC and GC patients (Figure $9 b$ ). Systemic IL-13 concentration was significantly higher in ESCC patients with lymph node involvement (11.6 pg/mL (9.8-13.7) in $\mathrm{N} \geq 1$ vs. $6.57 \mathrm{pg} / \mathrm{mL}$ (3.9-11.1) in N0, $p=0.014)$ and tended to be higher in ESCC patients with distant metastases (11.8 pg/mL (9.4-15) in $\mathrm{M} 1$ vs. $8.03 \mathrm{pg} / \mathrm{mL}$ (5.7-11.2) in M0, $p=0.089$ ). It positively correlated with tumor extension (T; $\rho=0.26, p=0.014)$ and tended to correlate with ESCC stage (TNM; $\rho=0.19, p=0.075)$. In CRC, systemic IL-13 significantly and positively correlated with tumor grade $(\rho=0.27, p=0.039)$ and tended to correlate with tumor extension $(\rho=0.21, p=0.080)$ and CRC stage $(\rho=0.21, p=0.077)$.

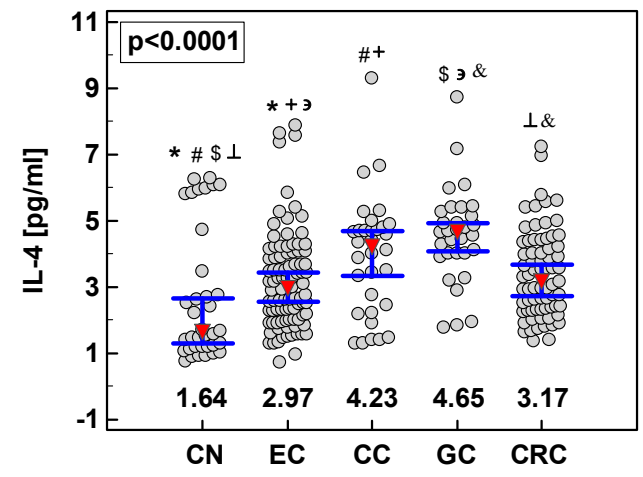

(a)

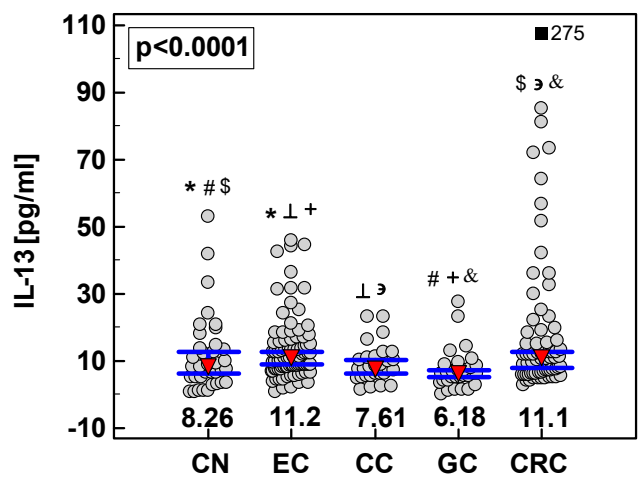

(b)

Figure 9. Systemic concentration of interleukins in gastrointestinal tract cancers: (a) IL-4; (b) IL-13. Data presented as medians (red triangles) with 95\% confidence interval (whiskers) and analyzed using Kruskal-Wallis $H$ test. Statistically significant differences between groups are marked with symbols of the same type $(*$, \#, etc.). CN, healthy controls; EC, patients with esophageal squamous cell carcinoma; CC, patients with adenocarcinoma of gastric cardia; GC, patients with gastric adenocarcinoma; CRC, patients with colorectal cancer. An outlying observation is marked by a closed square. 


\subsection{Effect of Exogenous IL-4 and IL-13 on Colon Cancer Cells-Preliminary Findings}

2.3.1. Expression of IL4 and IL13 and Their Receptors (IL4Ra and IL13Ra1) in Colon Cancer Cell Lines: Effect of Nutritional Stress, Chemically Induced Hypoxia, and IL-4 and IL-13

Three colonic cancer cell lines cultured in our laboratory, namely Caco-2, HCT 116, and HT-29 as well as biobanked cDNA from LoVo, SW480, and SW620 cells were screened for the expression of IL4, IL13, IL4Ra, and IL13Ra1. IL4 transcripts were expressed at low level in Caco-2 but were only barely detectable in HCT 116, HT-29, LoVo, and SW620 and undetectable in SW480 cells. IL13 transcripts were expressed at equally low level in Caco-2 and were undetectable in other cell lines.

In turn, all cell lines expressed IL4R $a$ and IL13Ra1. IL4Ra expression was significantly higher in Caco-2, HT-29, and LoVo cells than in HCT 116 and SW480. In addition, IL4Ra expression in SW620 was higher than in SW480 cells. IL13Ra1 expression was significantly higher in HT-29 and SW620 than in HCT 116 and SW480 cells (Figure 10).

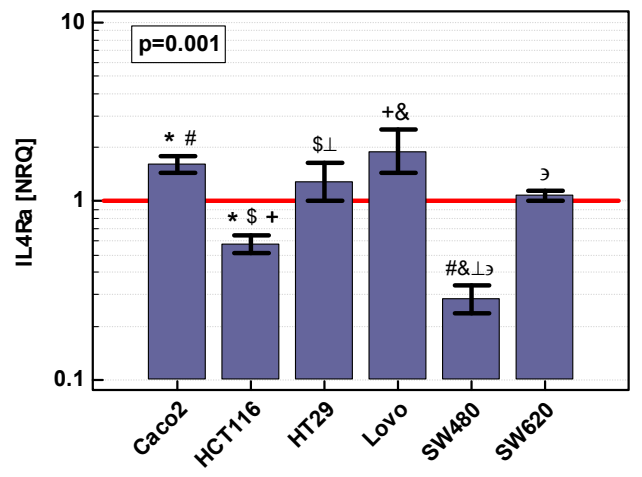

(a)

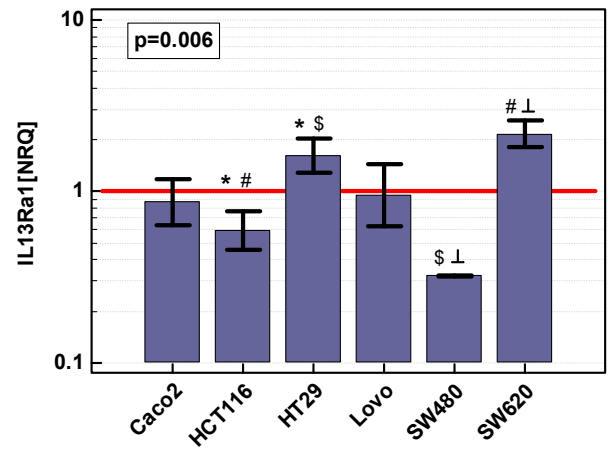

(b)

Figure 10. Relative expression of IL4Ra and IL13Ra1 in colon cancer cells lines: (a) IL4Ra; (b) IL13Ra1. Data analyzed as logs using one-way ANOVA and presented as geometric means \pm SE $(n=2-6)$ of normalized relative quantities [NRQ]. Expression levels were normalized against GAPDH expression and presented in relation to geometric mean of gene expression across all samples (represented by horizontal red line). Statistically significant differences between groups are marked with symbols of the same type $(*, \#$, etc. $)$.

Subsequently, potential effects of nutritional stress (serum withdrawal) and chemically induced hypoxia on IL4Ra and IL13Ra1 expression in Caco-2, HCT 116, and HT-29 cells was evaluated.

IL4Ra expression was slightly upregulated by serum starvation in HCT 116 and HT-29, but not Caco-2 cells. IL13Ra1 expression was significantly upregulated by serum starvation solely in HCT 116 cells (Figure 11a).

Chemically induced hypoxia ( $200 \mu \mathrm{M} \mathrm{CoCl}_{2}$ ) reduced IL4Ra expression to $30 \%$ in Caco-2 cells and to $54 \%$ in HCT 116 and 42 in HT29 cells. IL13Ra1 expression dropped to $45 \%$ in Caco-2 and to $47 \%$ in HCT 116 and 48\% in HT-29 cells (Figure 11b).

IL-4 has been shown to stimulate the expression of IL-4Ra in immune cells [31]. Therefore, the potential effect of IL-4 stimulation on IL4Ra and IL13RaI expression and of IL-13 on IL13RaI expression was evaluated.

IL4R $a$ and IL13Ra1 expression in Caco-2 cells was significantly downregulated by 24-h stimulation with IL-4 (250 ng/mL). A minor non-significant upregulation of IL4Ra in HCT 116 and downregulation in HT-29 could be observed as well (Figure 12a). IL13Ra1 expression was marginally upregulated in Caco-2 upon 24-h stimulation with IL-13 $(250 \mathrm{ng} / \mathrm{mL})$ but the effect did not reach statistical significance (Figure 12b). 


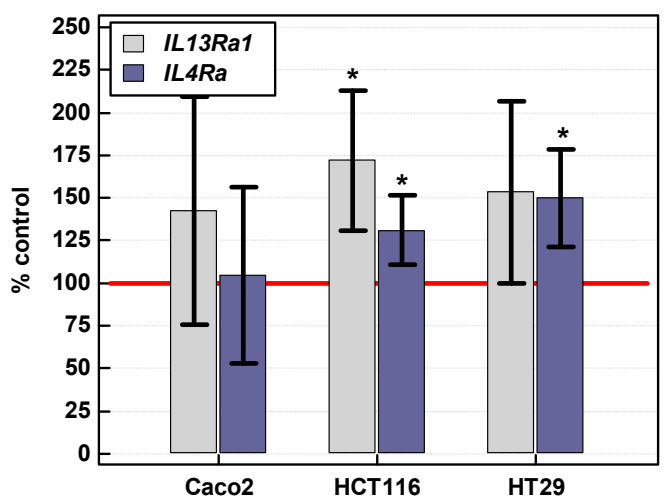

(a)

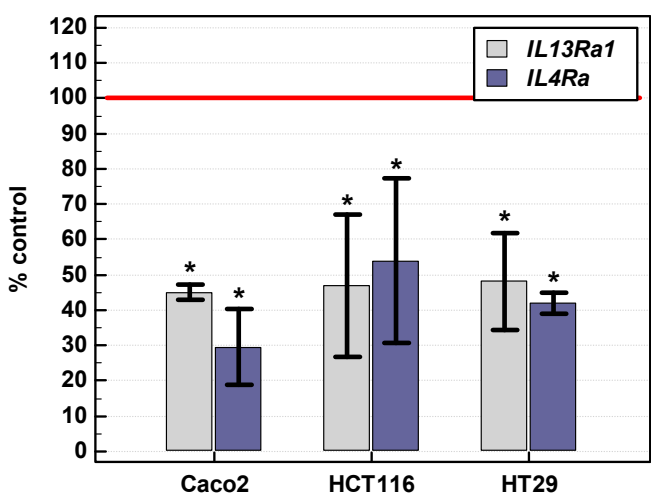

(b)

Figure 11. IL13RaI and IL4Ra expression under stress conditions: (a) serum withdrawal; (b) chemically induced hypoxia. Bars represent mean $(n=2-4)$ of relative expression of receptor transcripts in cells grown with $0.5 \%$ FBS or stimulated with $200 \mu \mathrm{M} \mathrm{CoCl}_{2}$ for $24 \mathrm{~h}$ as compared to controls (cells grown with $10 \%$ FBS or unstimulated), expressed as a percentage. Reference expression level of control/untreated cells $(100 \%)$ is represented by red horizontal line. Statistically significant differences in treated cells as compared to their respective controls are marked with asterisks $\left(^{*}\right.$ ) (analyzed using $t$-test for one mean).

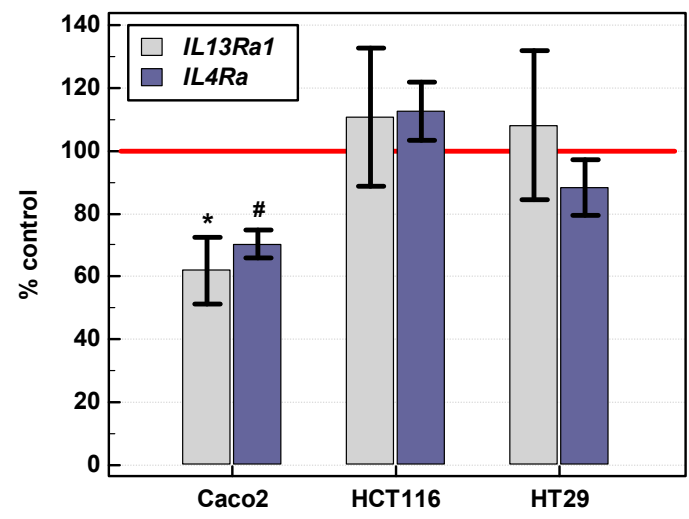

(a)

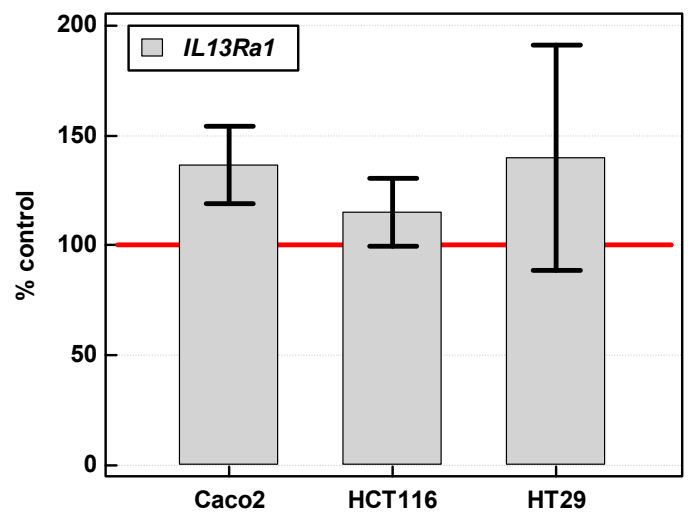

(b)

Figure 12. Effect of IL-4 and IL-13 on their respective receptor expression: (a) IL13Ra1 and IL4 expression following 24-h stimulation with $250 \mathrm{ng} / \mathrm{mL}$ of IL-4; (b) IL13Ra1 expression following 24-h stimulation with $250 \mathrm{ng} / \mathrm{mL}$ of IL-13. Bars represent mean $\pm \mathrm{SE}(n=4)$ of relative expression of receptor transcripts in stimulated as compared to unstimulated (controls) cells expressed as a percentage. Reference expression level of untreated cells $(100 \%)$ is represented by red horizontal line. Statistically significant differences in treated cells as compared to their respective controls, analyzed using $t$-test for one mean, are marked as follows: $p<0.05$ as $* ;<0.01$ as \#.

\subsubsection{Effect of IL-4 and IL-13 on Viability of Colon Cancer Cells}

Available literature presents contradicting data concerning effects of IL-4 and IL-13 on cancer cell proliferation and ability to evade pro-apoptotic signals. Therefore, we evaluated the interleukin impact on viability of colon cancer cells using sulforhodamine B (SRB) assay under normal growth conditions (cells cultured with 10\% FBS) and under nutritional stress (cells cultured with $0.5 \%$ FBS). Subsequently, expression of genes encoding proliferation marker Ki67, anti-apoptotic proteins BCL-2 and BCL-xL, and cell cycle regulator $\mathrm{p} 21^{\mathrm{CIP} 1 / \mathrm{WAF} 1}$ in colon cancer cells stimulated with IL-4 or IL-13 was determined. 
Viability Assay

Under normal growth conditions (10\% FBS), IL-4 increased cell density by several to twenty percent in HCT 116 and HT-29 lines. Caco-2 cells response was less consistent but showed more marked growth acceleration (up-to $150 \%$ of control culture growth). Stimulatory effect of IL-4 was observed long-term in HCT 116 but short-term in Caco-2 cells. Moderate interleukin concentration, $5-100 \mathrm{ng} / \mathrm{mL}$, was more effective while prolonged stimulation with $250 \mathrm{ng} / \mathrm{mL}$ of IL-4 tended to be inhibitory (Figure 13a,c,e).
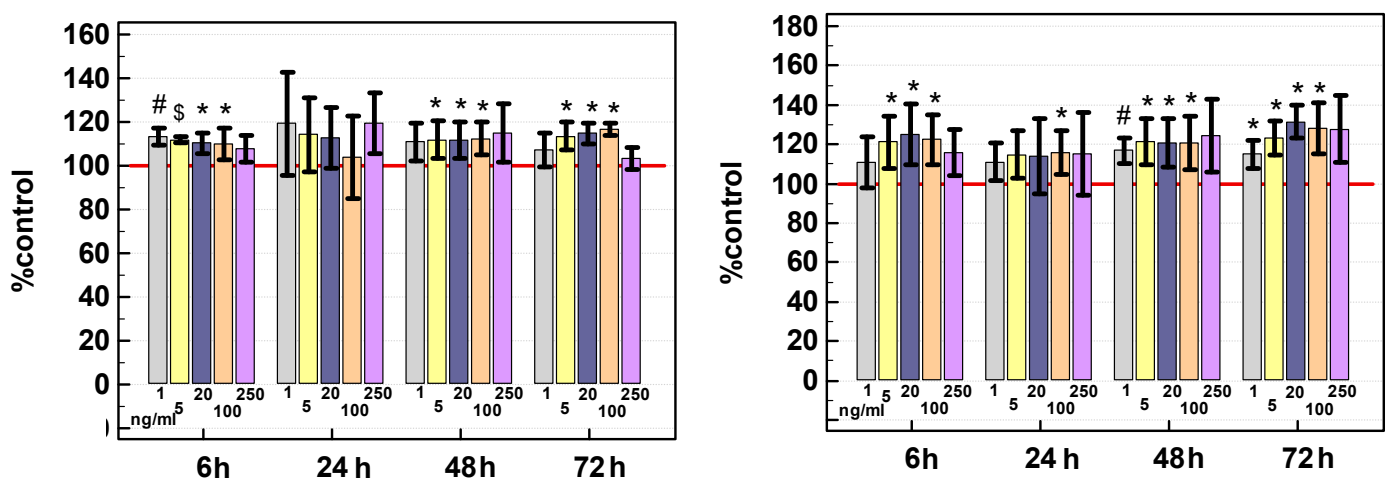

(a)
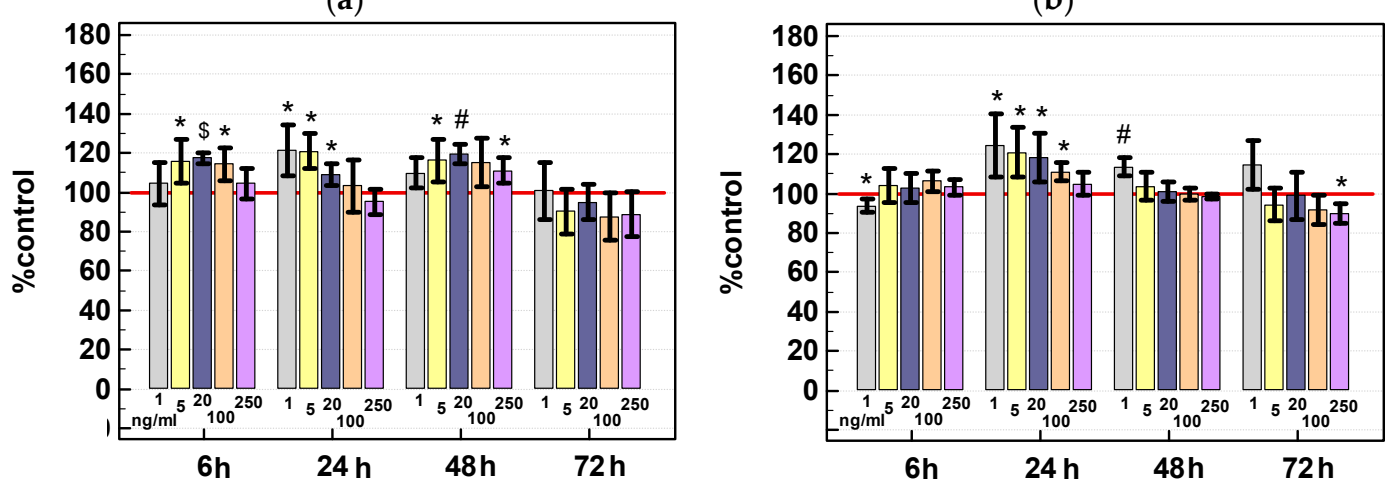

(c)

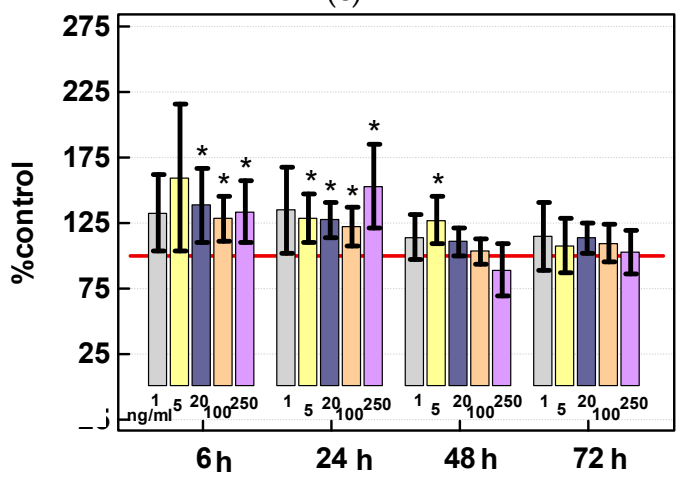

(e)

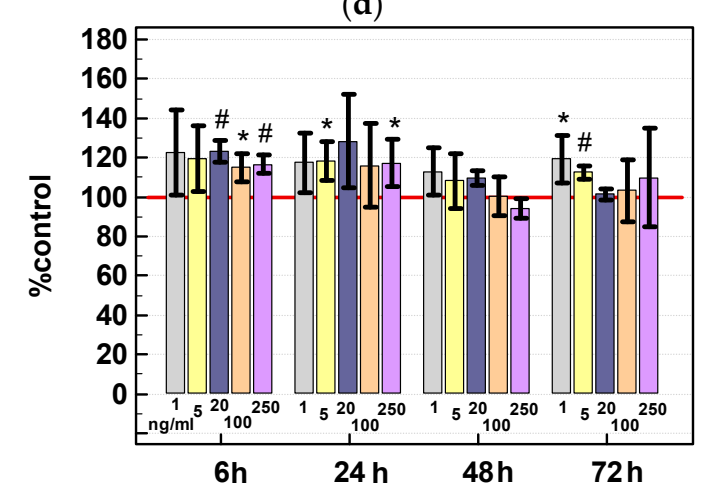

(f)

Figure 13. Effect of exogenous IL-4 (1-250 ng/mL) on cancer cell viability under normal (10\% FBS) and nutritional-stress (0.5\% FBS) conditions as determined with sulforhodamine B (SRB) assay: (a) HCT 116 cultured in 10\% FBS; (b) HCT 116 cultured in 0.5\% FBS; (c) HT-29 cultured in 10\% FBS; (d) HT-29 cultured in $0.5 \%$ FBS; (e) Caco-2 cultured in 10\% FBS; (f) Caco-2 cultured in 0.5\% FBS. Data presented as percentage ( $\%$ control) of viability of unstimulated cells, marked at $100 \%$ as reference red horizontal line. Statistically significant differences in treated cells as compared to their respective controls, analyzed using $t$-test for one mean, are marked as follows: $p<0.05$ as $* ; p<0.01$ as \#; $p<0.001$ as $\$$. Bars represent means \pm SE of at least three experiments. FBS, fetal bovine serum. 
Under nutritional stress conditions (0.5\% FBS), stimulation with IL-4 resulted in accelerated growth in HCT 116 cells by 20-30\%, especially in 72-h cultures, while the response of HT-29 and Caco-2 cells was weaker (Figure 13b,d,f).

Under normal growth conditions (10\%FBS), IL-13 increased HCT 116 cell density by several to twenty five percent and the stimulatory effect was observed in 48-h cultures. The interleukin was more effective in HCT 116 cells grown under nutritional stress conditions ( $0.5 \%$ FBS). Cell density in 48-h cultures was higher by $40 \%$ and the stimulatory effect was observed in 48 - and 72 -h cultures. Short-term stimulation with IL-13 accelerated growth of HT-29 cells by $40 \%$. Under nutritional stress conditions, the stimulatory effect of low interleukin concentration was observed in 48- and 72-h cultures. There was no or weak response to IL-13 in Caco-2 cells regardless the growth conditions (Figure 14).

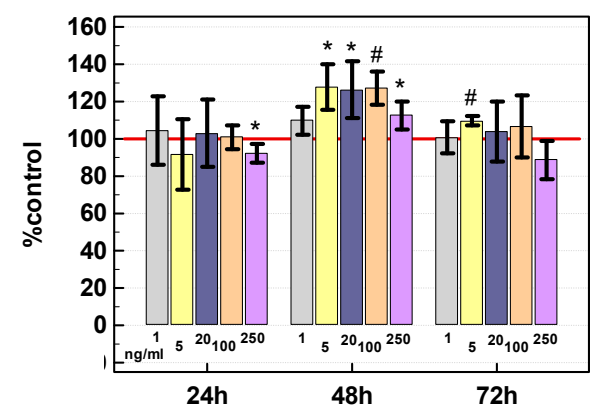

(a)

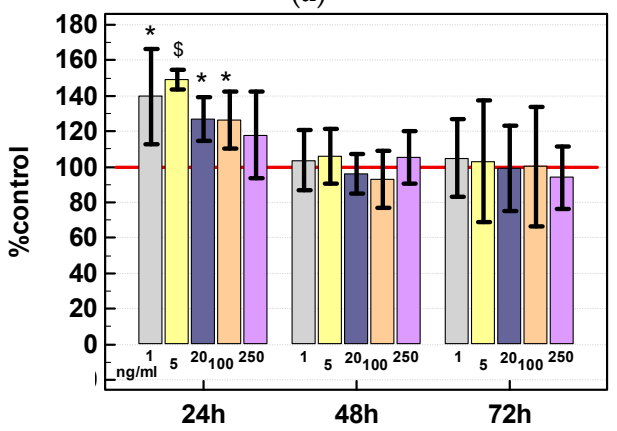

(c)

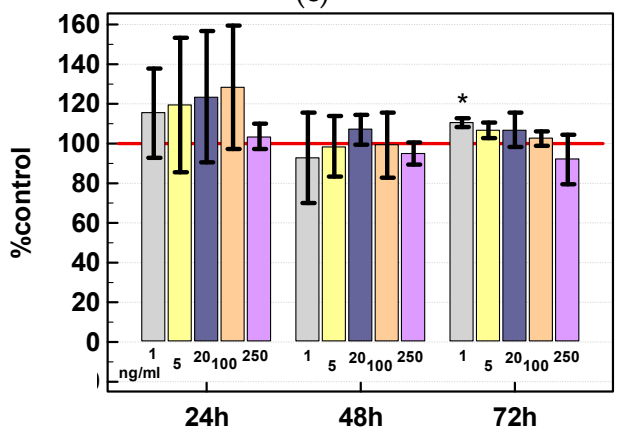

(e)

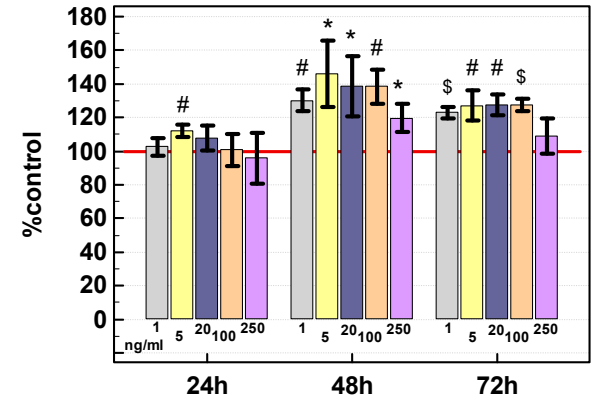

(b)

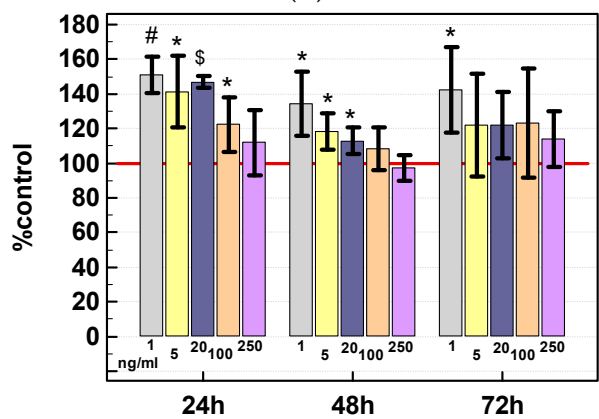

(d)

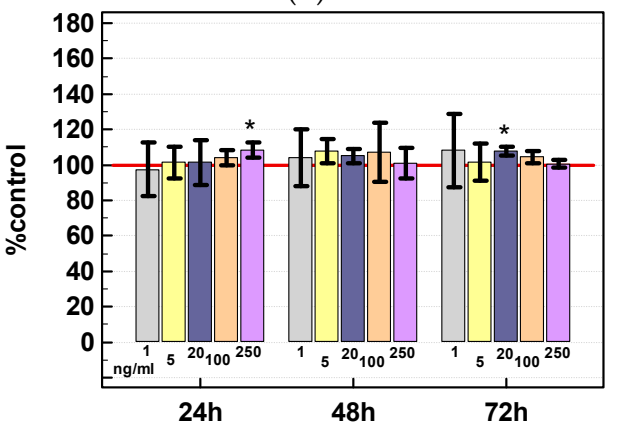

(f)

Figure 14. Effect of exogenous IL-13 (1-250 ng/mL) on cancer cell viability under normal (10\% FBS) and nutritional-stress (0.5\% FBS) conditions as determined with sulforhodamine B (SRB) assay: (a) HCT 116 cultured in 10\% FBS; (b) HCT 116 cultured in 0.5\% FBS; (c) HT-29 cultured in 10\% FBS; (d) HT-29 cultured in $0.5 \%$ FBS; (e) Caco-2 cultured in 10\% FBS; (f) Caco-2 cultured in 0.5\% FBS. Data presented as percentage (\% control) of viability of unstimulated cells, marked at $100 \%$ as reference red horizontal line. Statistically significant differences in treated cells as compared to their respective controls, analyzed using $t$-test for one mean, are marked as follows: $p<0.05$ as $* ;<0.01$ as \#; $p<0.001$ as $\$$. Bars represent means \pm SE of at least three experiments. FBS, fetal bovine serum. 


\section{Gene Expression}

Increased cell viability may result from accelerated proliferation or increased resistance to apoptosis. Therefore, potential IL-4 and IL-13 effect on expression of genes encoding representative proteins relevant for either process was determined.

IL-4 stimulation had negative impact on Caco-2 cells, significantly decreasing the expression of BCL2, BCLxL, and Ki67 and non-significantly that of CDKN1A (p21 $\left.{ }^{\mathrm{CIP} 1 / \mathrm{WAF} 1}\right)$. IL-4 slightly but significantly upregulated BCL2 and Ki67 expression in HCT 116 cells and more markedly BCL2 expression, but the effect did not reach statistical significance (Figure 15a).

IL-13 stimulation significantly decreased BCLxL expression in Caco-2 cells and upregulated that of Ki67 in HT-29 cells (Figure 15b).

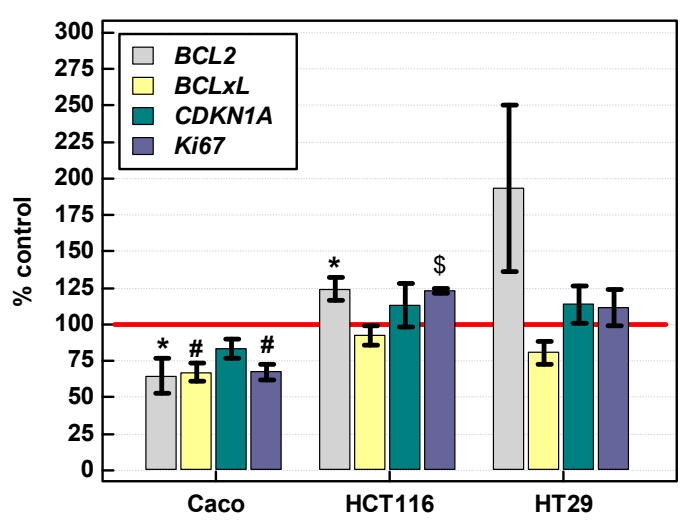

(a)

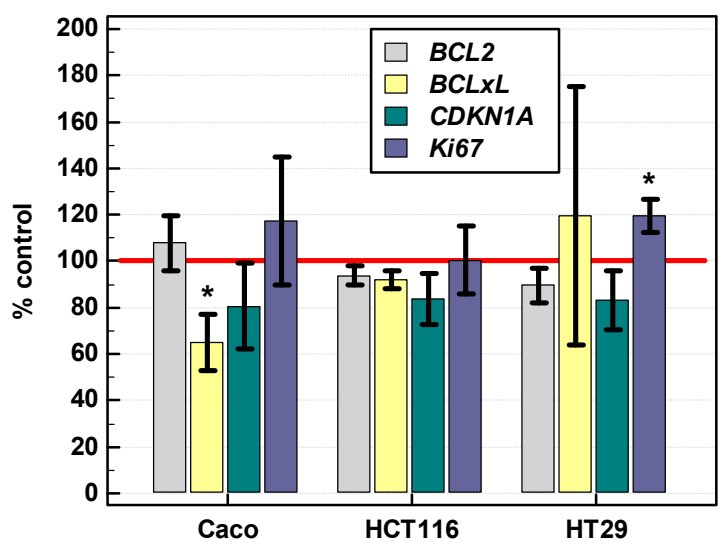

(b)

Figure 15. Effect of IL-4 and IL-13 stimulation on the expression of mediators of proliferation and apoptosis: (a) 24-h stimulation with $250 \mathrm{ng} / \mathrm{mL}$ of IL-4; (b) 24-h stimulation with $250 \mathrm{ng} / \mathrm{mL}$ of IL-13. Bars represent mean $\pm \mathrm{SE}(n=4)$ of relative gene expression in stimulated as compared to unstimulated (control) cells expressed as a percentage. Reference expression level of untreated cells (100\%) is represented by red horizontal line. Statistically significant differences in treated cells as compared to their respective controls, analyzed using $t$-test for one mean, are marked as follows: $p<0.05$ as *; $p<0.01$ as \#; $p<0.001$ as $\$$.

2.3.3. Effect of IL-4 and IL-13 on Motility of Colon Cancer Cells and Expression of Motility-Related Genes

IL-4 has recently been shown to enhance motility of colon cancer cells. Here, we evaluated the effect of IL-4 and IL-13 on cell motility using scratch assay. Subsequently, we analyzed the interleukin impact on genes encoding motility-related proteins: ACTA2, encoding EMT marker smooth muscle $\alpha-2$ actin, and TJP1 and CLDN2, encoding, respectively, tight junction proteins zonula occludens-1 and claudin-2.

\section{Scratch Assay}

Scratch assay was used to evaluate the effect of exogenous IL-4 and IL-13 (100 ng/mL) on the migratory properties of cancer cells recorded at $0,24,48$, and $72 \mathrm{~h}$.

Both IL-4 and IL-13 stimulated motility of Caco-2 and HCT 116 cells. Analysis of data pooled from several biological experiments showed accelerated migration upon IL-4 and IL-13 stimulation at $48 \mathrm{~h}$ in Caco-2 and already at $24 \mathrm{~h}$ in HCT 116 cells. IL-13 seemed to be more effective than IL-4 in Caco-2 cells while IL-4 was more effective in HCT 116 (Figure 16). Photographs of exemplary scratch assay are depicted in Figure 17 for HCT 116 cells and in Figure 18 for Caco- 2 cells. The migratory properties of HT-29 cells were generally low and the gap was not closed in control culture even after $144 \mathrm{~h}$. Therefore, only IL-4 effect was tested and none was found. 


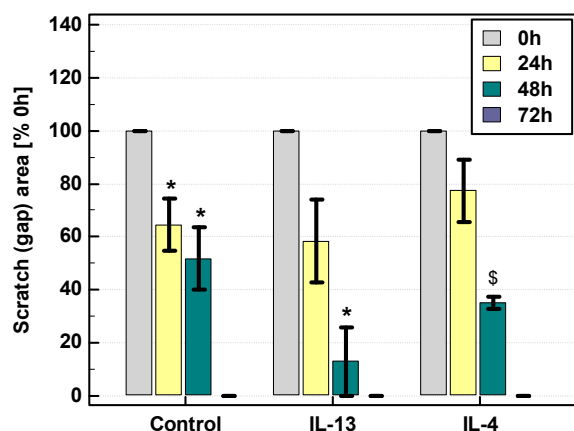

(a)

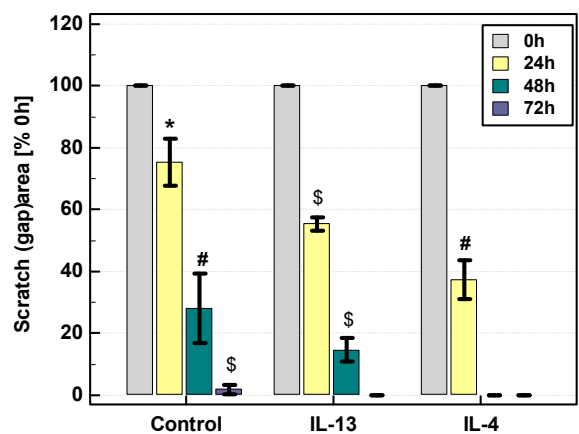

(b)

Figure 16. Analysis of the scratch assay data. Effect of IL-4 and IL-13 stimulation $(100 \mathrm{ng} / \mathrm{mL})$ on: (a) Caco-2 cells; (b) HCT 116 cells. Results at each time point are expressed as a percentage of gap area considering the gap at the time 0 as $100 \%$. Each bar represents mean \pm SE of three (Caco-2) or four (HCT116) biological replicates. Statistically significant differences as compared to time 0 , analyzed using $t$-test for one mean, are marked as follows: $p<0.05$ as $* ;<0.01$ as \#; $p<0.001$ as $\$$.

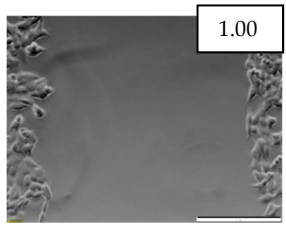

(a)

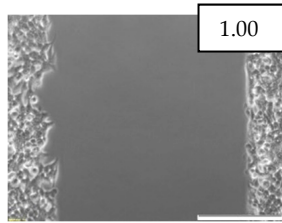

(e)

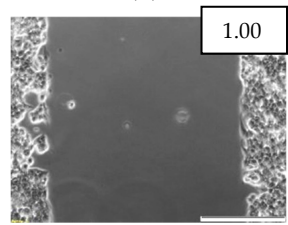

(i)

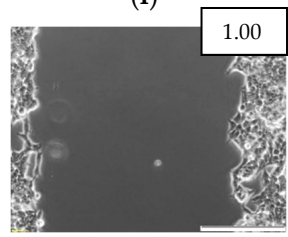

(m)

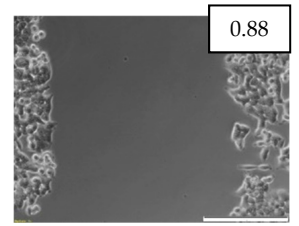

(b)

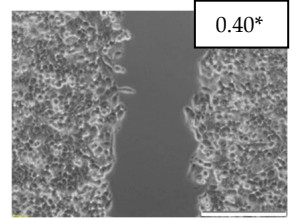

(f)

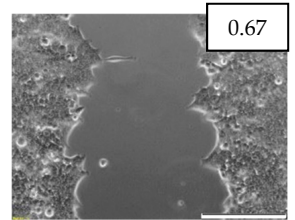

(j)

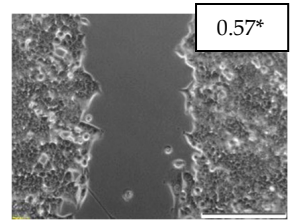

(n)

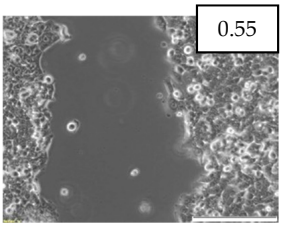

(c)

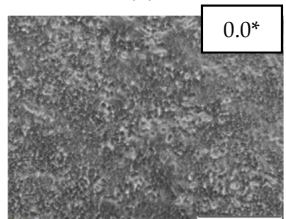

(g)

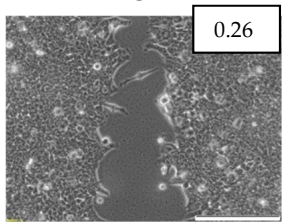

(k)

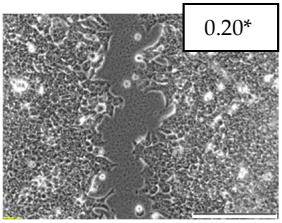

(o)

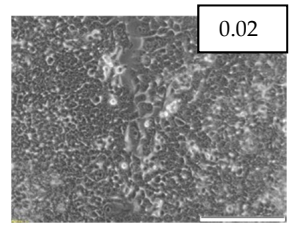

(d)

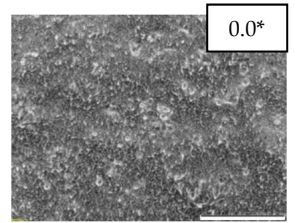

(h)

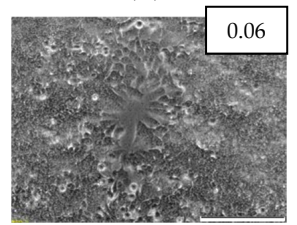

(1)

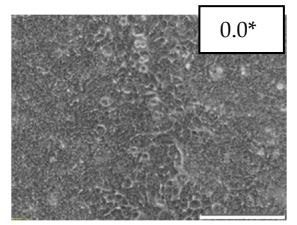

(p)

Figure 17. Impact of stimulation with $100 \mathrm{ng} / \mathrm{mL}$ of IL-4 or IL-13 on HCT 116 cells-a scratch assay (representative data): (a) control for IL-4 at 0 h; (b) control for IL-4 at 24 h; (c) control for IL-4 at 48 h; (d) control for IL-4 at $72 \mathrm{~h}$; (e) stimulated with IL-4 at $0 \mathrm{~h}$; (f) stimulated with IL-4 at $24 \mathrm{~h}$; (g) stimulated with IL-4 at 48 h; (h) stimulated with IL-4 at 72 h; (i) control for IL-13 at 0h; (j) control for IL-13 at 24 h; (k) control for IL-13 at $48 \mathrm{~h}$; (1) control for IL-13 at $72 \mathrm{~h}$; (m) stimulated with IL-13 for $0 \mathrm{~h}$; (n) stimulated with IL-13 at 24 h; (o) stimulated with IL-13 at 48 h; (p) stimulated with IL-13 at $72 \mathrm{~h}$. Scale bars (200 $\mu \mathrm{m})$ are indicated in lower right corner of each photograph. Numeric data in the upper right corner of each photograph indicate a ratio of gap (scratch) area at given time point to gap area at time 0 . The ratios in interleukin-stimulated cells significantly $(p<0.01)$ different from their unstimulated counterparts are marked with asterisks $\left({ }^{*}\right)$. 


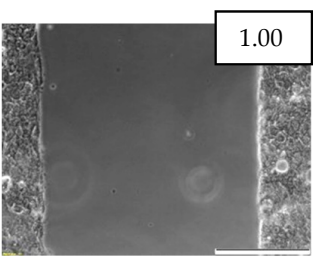

(a)

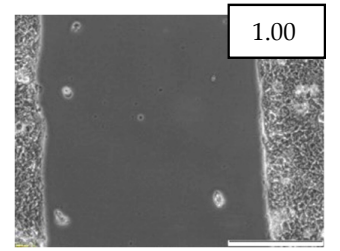

(e)

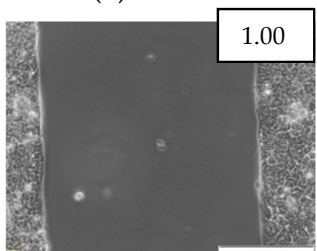

(i)

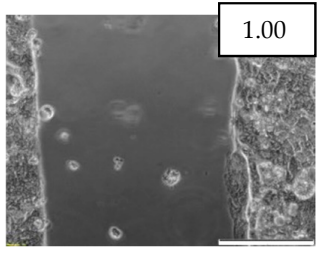

(1)

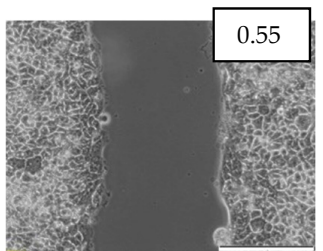

(b)

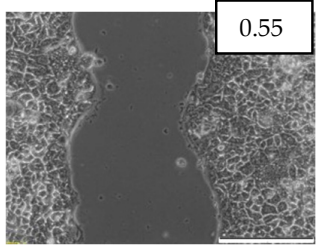

(f)

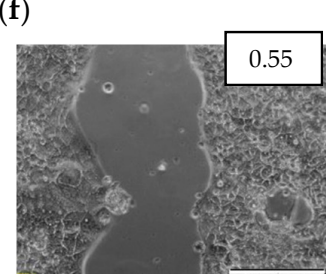

(j)

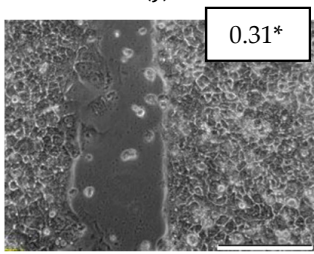

(m)

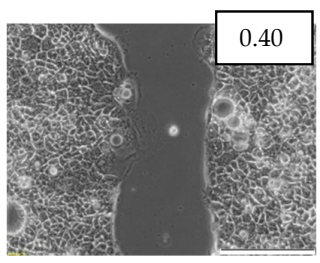

(c)

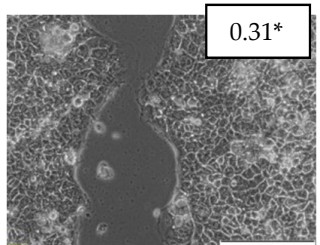

(g)

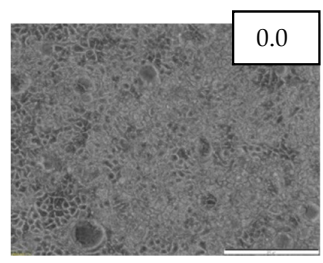

(d)

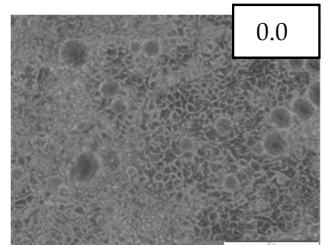

(h)

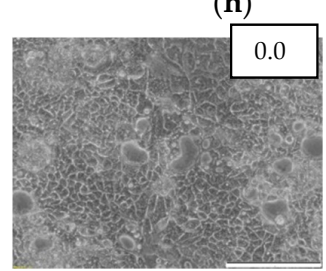

(k)

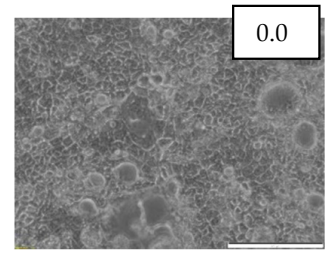

(n)

Figure 18. Impact of stimulation with $100 \mathrm{ng} / \mathrm{mL}$ of IL-4 or IL-13 on Caco-2 cells-a scratch assay (representative data): (a) control for IL-4 at 0 h; (b) control for IL-4 at 24 h; (c) control for IL-4 at 48 h; (d) control for IL-4 at $72 \mathrm{~h}$; (e) stimulated with IL-4 at $0 \mathrm{~h}$; (f) stimulated with IL-4 at $24 \mathrm{~h}$; (g) stimulated with IL-4 at 48 h; (h) stimulated with IL-4 at 72 h; (i) control for IL-13 at 0 h; (j) control for IL-13 at $24 \mathrm{~h}$; (k) control for IL-13 at $48 \mathrm{~h}$; (1) stimulated with IL-13 at $0 \mathrm{~h}$; (m) stimulated with IL-13 at $24 \mathrm{~h}$; (n) stimulated with IL-13 at $48 \mathrm{~h}$. Scale bars $(200 \mu \mathrm{m})$ are indicated in lower right corner of each photograph. Numeric data in the upper right corner of each photograph indicate a ratio of gap (scratch) area at given time point to gap area at time 0 . The rates in interleukin-stimulated cells significantly $(p<0.01)$ different from their unstimulated counterparts are marked with asterisks $\left(^{*}\right)$.

Gene Expression

Stimulation with IL-4 (250 ng/mL) for 24-hs had consistently positive effect on CLDN2 expression across all analyzed cell lines. In addition, IL-4 downregulated ACT2 and TJP1 expression in Caco-2 cells (Figure 19a). The expression of CLDN2 was upregulated and those of ACTA2 and TJP1 downregulated in all cell lines following IL-13 stimulation $(250 \mathrm{ng} / \mathrm{mL}, 24 \mathrm{~h})$ but the effect did not reach statistical significance due to large variation between biological replicates of the experiment (Figure 19b). 


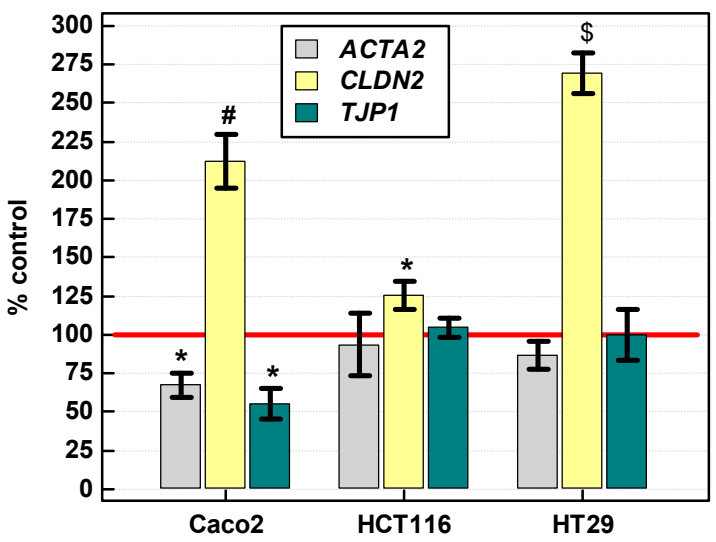

(a)

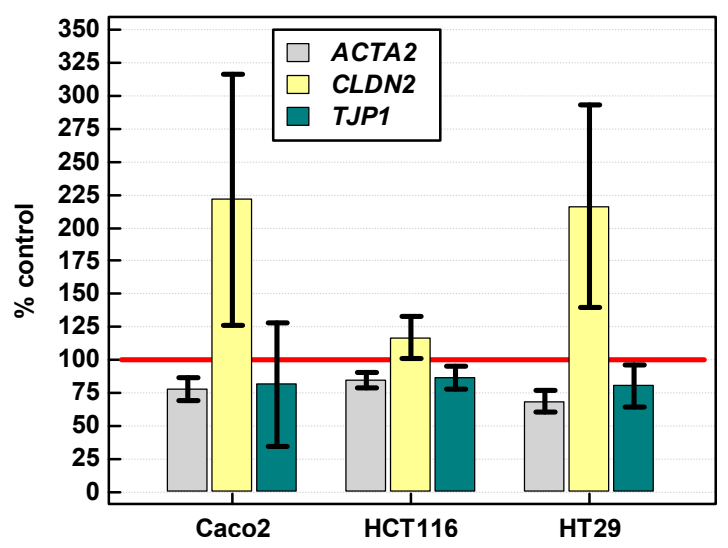

(b)

Figure 19. Effect of IL-4 and IL-13 stimulation on the expression of epithelial-mesenchymal transition markers and tight junction proteins: (a) 24-h stimulation with $250 \mathrm{ng} / \mathrm{mL}$ of IL-4; (b) 24-h stimulation with $250 \mathrm{ng} / \mathrm{mL}$ of IL-13. Bars represent mean $\pm \mathrm{SE}(n=4)$ of relative gene expression in stimulated as compared to unstimulated (controls) cells expressed as a percentage. Reference expression level of untreated cells (100\%) is represented by red horizontal line. Statistically significant differences in treated cells as compared to their respective controls, analyzed using $t$-test for one mean, are marked as follows: $p<0.05$ as * $p<0.01$ as \#; $p<0.001$ as $\$$.

\subsubsection{Effect of IL-4 and IL-13 on Expression of Various Cancer Development-Related Genes}

Potential effect of IL-4 and IL-13 ( $250 \mathrm{ng} / \mathrm{mL}, 24 \mathrm{~h})$ on the expression of genes encoding proteins relevant for cancer development by facilitating angiogenesis (HIF1A and VEGFA), inflammation (PTGS2, NOS2, CCL2), and metabolic reprogramming (GLUT1, ODC1, NOS2) was evaluated. IL-4 downregulated all assessed genes in Caco-2 cells and GLUT1 in HCT 116 cells while upregulating VEGFA in HT-29 cells (Figure 20a). IL-13 significantly downregulated HIF1A and PTGS2 in HT29 cells (Figure 20b). Expression of CCL2 and NOS2 in HCT 116 and HT-29 cells was too low to be reliably quantified. In turn, HCT 116 cells reportedly do not express PTGS2 [32].

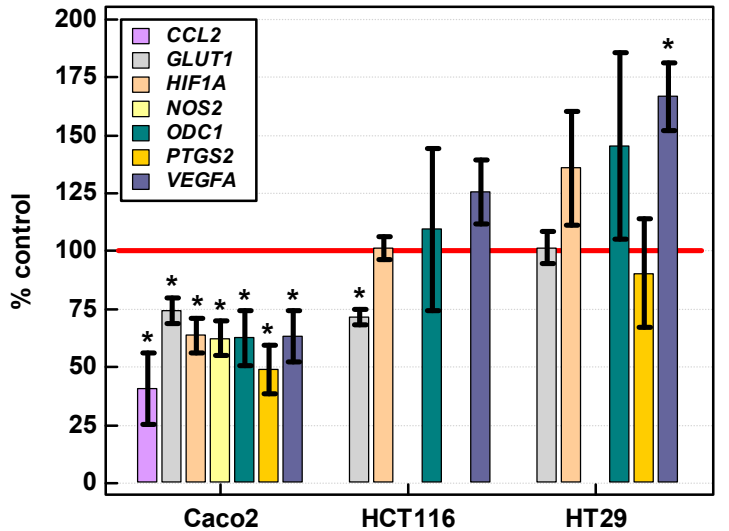

(a)

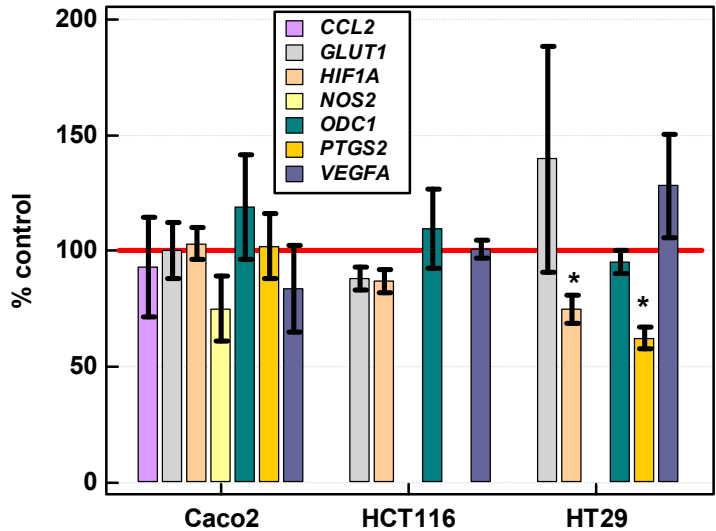

(b)

Figure 20. Effect of IL-4 and IL-13 stimulation on expression of various proteins relevant for cancer growth: (a) 24-h stimulation with $250 \mathrm{ng} / \mathrm{mL}$ of IL-4; (b) 24-h stimulation with $250 \mathrm{ng} / \mathrm{mL}$ of IL-13. Bars represent mean $\pm \mathrm{SE}(n=4)$ of relative gene expression in stimulated as compared to unstimulated (controls) cells expressed as a percentage. Reference expression level of untreated cells (100\%) is represented by horizontal red line. Statistically significant differences $(p<0.05)$ in treated cells as compared to their respective controls, analyzed using $t$-test for one mean, are marked with asterisks $\left(^{*}\right)$. 


\section{Discussion}

The role of IL-4 and IL-13 in leukocyte biology and hematological malignancies is well established and their involvement in activation of cancer-promoting macrophages and myeloid-derived suppressor cells is increasingly being recognized $[7,8]$. However, it becomes apparent that both interleukins may directly affect the growth and progression of epithelial cancers if their cells express suitable receptors $[7,8]$. The presence of IL-4R $\alpha$ protein has previously been demonstrated in the majority of investigated colonic [20,26] and gastric [25] tumors but data concerning esophageal cancer are scarce. Filling the gaps, we demonstrated that all examined tumor biopsies had detectable levels of receptor mRNA, including esophageal squamous cell carcinomas. More so, IL4Ra in esophageal tumors tended to increase along with growing cell dedifferentiation, apparently linking receptor expression with higher tumor aggressiveness. In CRC, however, IL4Ra expression was lower than in upper GIT tumors and was not associated with cancer pathology. Transcriptional analysis of clinical samples revealed positive correlation between $I L 4 R a$ and expression of negative regulators of apoptosis, markers of epithelial-mesenchymal transition, and mediators of inflammation and angiogenesis. While it might be viewed as an argument supporting pro-neoplastic character of IL4Ra expression, cellular composition of tumors is complex and our in vitro experiments showed that cancer cells specifically respond to cancer-promoting hypoxia with receptor down-regulation. Correspondingly, others have shown that high IL-4R $\alpha$ protein expression in CRC was associated with lower incidence of lymph node metastasis [26]. Supporting the possible anti-neoplastic role for IL-4R $\alpha$, the experiments on knockout animals have revealed higher number of colorectal aberrant crypt foci following azoxymethane induction in animals lacking the receptor [27]. Nonetheless, functional studies regarding other epithelial cancers have shown IL-4R $\alpha$ to facilitate the proliferation and survival of cancer cells at metastatic sites [33].

Likewise, IL13Ra1 transcripts were detectable in all examined tumor samples and their expression level was the lowest in colonic samples, both cancerous and non-cancerous. Unlike the other IL-13 receptor, IL-13R $\alpha 2$, data on IL-13R $\alpha 1$ in the GIT cancers are limited and inconclusive. Previously, IL-13R $\alpha 1$ protein expression has been demonstrated in the colon, in both adenomas [34] and adenocarcinomas [26,34]. However, immunoreactivity for IL-13R $\alpha 1$ was markedly lower in colonic samples from patients with lymph node involvement, implying anti-neoplastic connotation for IL-13R $\alpha 1$ expression [26]. In turn, the upregulation of IL-13R $\alpha 2$ has been reported in colorectal [10] and gastric [16] cancers and linked with local advancement and metastasis [10] as well as poor prognosis $[10,16]$. Corroborating potentially tumor-promoting role also for IL-13R $\alpha 1$, Matsui et al. [18] demonstrated co-expression of the receptor with proliferation indices in mice with obesity-related CRC. Moreover, the authors showed an inhibition of colonic cancer cell proliferation induced by IL-13 by silencing IL13Ra1, but not IL13Ra2 gene. We, in turn, observed IL13Ra1 in tumors to correlate positively with expression of genes encoding proteins involved in promoting cancer, especially those facilitating invasion and metastasis such as $\alpha$ smooth muscle actin, HIF1 $\alpha$, and VEGF-A, although not with proliferation marker Ki67. Like IL4Ra, however, IL13Ra1 expression in colonic cancer cells was uniformly downregulated under hypoxia.

Clinical data on IL-4, a primary ligand for IL-4R $\alpha$, are equivocal. Here, IL-4 protein was upregulated at both local and systemic level and regardless the anatomical site. However, while the local protein concentration was the highest in CRC and the lowest in GC, circulating IL-4 was more markedly elevated in GC than CRC. This finding might imply a more immunosuppressive tumor microenvironment in CRC and provide rationale for its poor responsiveness to checkpoint blockade, the otherwise successful antitumor strategy based on alleviating tumor-induced inhibition of adaptive immunity [35]. Nonetheless, it has been put forward that systemic elevation of Th2 cytokines, observed here particularly in gastric cancer, may indicate a generalized state of immunosuppression and still promote cancer growth and dissemination [36]. Different association patterns for local and systemic IL-4, concerning sex-dependence [15,37] and relation with the disease advancement $[13,14]$, have been noted also by other authors. Regarding CRC, previous studies have shown circulating 
IL-4 to be too low to be quantified [38] or, in contrary, elevated [39-41] and suitable as a CRC biomarker. Moreover, in favor of its cancer-supporting role, IL-4 elevation has been directly linked with higher mortality [42]. In addition, interleukin concentration has been increased in right-sided colonic cancers [39], considered more aggressive and associated with worse prognosis [43-45]. Furthermore, the interleukin over-secretion has been confirmed already in conditions associated with increased risk of CRC, that is, in ulcerative colitis [46] and adenomatous polyps [41]. Unlike in CRC or esophageal cancer $[47,48]$, an elevation in systemic IL-4 has been unanimously reported in GC [37,47,49], even though its association with pathological findings was inconsistent. On the one hand, IL-4 has been more markedly elevated in patients with higher modified Glasgow Prognostic Score, thus with worse prognosis, but lower in those with more advanced cancers, that is, with vascular invasion or N3 cancers, on the other [49].

Contrary to systemic interleukin concentration, its local protein level in our patients depended on tumor aggressiveness and cancer advancement in ESCC and GC patients, respectively. Interestingly, however, only in GC the correlation resulted from IL-4 accumulation in tumor. In ESCC, the increasing difference in interleukin concentration between tumor and non-cancerous tissue stem from its decrease in adjacent tissue, inversely proportional to tumor grade, implying a protective role for the interleukin. Likewise, IL-4 protein concentration in colonic non-cancerous tumor-adjacent tissue decreases along with increasing tumor grade. Although Todaro et al. [12] suggested a possibility of autocrine mode of IL-4 signaling, we found that IL4 transcripts were detectable exclusively in one out of six investigated cell lines and their expression level was low. It would suggest that interleukin downregulation in adjacent tissue is not contributed to tumor cells. More likely, it is associated with its decreased secretion by other cell types and/or reflects alterations in cellular composition, with reduced number of IL-4 secreting cells. In line with declining IL-4 concentration along with increasing cancer aggressiveness in ESCC and CRC, IL4 expression was lower in ESCC cancers metastasizing to lymph nodes and tended to be inversely correlated with primary tumor extension in CRC. In turn, consistently with data regarding interleukin concentration, IL4 expression in gastric tumors tended to increase with the disease advancement. Whether IL-4 plays a protective or cancer-promoting role in GIT carcinogenesis is controversial. Supporting notion on protective function, lower IL-4 immunoreactivity has been demonstrated in colorectal tumors from CRC patients with lymph node metastases [26] or gastric tumors from patients with stage III/IV cancers [15]. In addition, IL-4 immunoreactivity inversely correlated with the presence of gastric metaplasia or cancer and with degree of inflammation [14]. Corroborating the latter observation, the expression of IL4 transcripts in our clinical samples correlated negatively with inducible nitric oxide synthase, an enzyme involved in inflammatory response and oxidative stress. Yet, the association was found solely in tumors while in non-cancerous tissue IL4 positively correlated with the expression of cyclooxygenase 2 (COX2) and monocyte chemoattractant protein 1 (MCP-1). Regarding MCP-1, IL-4 and MCP-1 are reportedly involved in a "self-amplifying loop" in tumor microenvironment, whereby interleukin promotes MCP1 expression by endothelial cells, which, in turn, induces Th2 differentiation by up-regulating IL-4 synthesis [50]. Caco-2 cells, however, responded to IL-4 stimulation with downregulation of NOS2 and COX2 and MCP1 encoding genes, PTGS2 and CCL2. Likewise, IL-4 downregulated the expression of PTGS2 in another epithelial cancer, that is, non-small cell lung cancer cells [51]. Taking into account a wide spectrum of cancer-promoting activities of MCP-1 or COX2, the downregulation of their expression induced by IL-4 seem to support anti-neoplastic character of the interleukin. Still, others have shown that IL-4 may initiate the carcinogenesis by triggering the premalignant differentiation of gastric epithelia [19] or by reducing squamous cell markers in the esophagus and inducing columnar differentiation with expression of columnar markers (reviewed in [21]). In the colon, IL-4 has stimulated invasion and metastasis by promoting the epithelial-mesenchymal transition via activation of STAT6 and transcriptional repressors Zeb [52].

While GC patients had the highest circulating IL-4, they had also the lowest concentration of IL-13, significantly lower even than enrolled controls. Elevated systemic IL-13 reflected the disease 
advancement in ESCC, particularly the presence of lymph node metastasis and the depth of tumor invasion, and tended to correlate positively with cancer stage and tumor grade in CRC. Fold-change in IL-13 protein concentration in the colorectum correlated positively with lymph node involvement and the disease stage. Like IL-4, IL-13 dropped in non-cancerous tissue. Contrary to IL-4, however, IL-13 protein concentration in esophageal cancerous and non-cancerous tissue increased along with ESCC advancement while in gastric tissue-decreased. Also differently than observed for IL-4, IL-13 protein concentration and IL13 transcript expression displayed different association patterns with pathological findings. IL13 in CRC correlated inversely with lymph node metastasis and TNM due to its increasing expression in non-cancerous tissue, paralleling increasing cancer advancement. Available literature on IL-13 in the GIT cancers is even scantier than that concerning IL-4. In CRC, high systemic IL-13 translated into better prognosis and accompanied less advanced cancers in terms of the overall disease stage and lymph node and distant metastases [24]. In ESCC, the density of IL-13 protein in tumor stroma has been higher in early cancers and positively associated with overall and disease-free survival [23]. Correspondingly, IL13 in clinical samples was inversely related to the expression of GLUT1, the upregulation of which is a hallmark of cancer-related metabolic reprogramming. In addition, it correlated negatively with anti-apoptotic BCL2 and proinflammatory NOS2, corroborating notion on beneficial interleukin role. Stimulation with IL-13 downregulated PTGS2 expression in HT-29 cells and reduced that of HIF1A, although IL13 in clinical samples was correlated positively with $V E G F A$, a HIF1 $\alpha$-inducible key mediator of angiogenesis. Nonetheless, contradicting the implied protective role [23], animal studies have implicated IL-13 in the development of metaplasia during gastric carcinogenesis (reviewed in [22]) and obesity-related CRC [18] while our own results have shown systemic interleukin to be elevated in both CRC [39] and high-risk conditions [46].

One of the important findings of this study is the observation that some of the alterations concerning interleukins are happening in the tumor-adjacent tissue and not the tumor itself. There is growing awareness that the macroscopically normal tumor-surrounding tissue may be changed at molecular level. While insufficient to affect cell morphology, it may predispose to neoplastic transformation. This phenomenon is believed to contribute to synchronous multiple cancers and to the disease recurrence following tumor resection. Curative resection remains the mainstay in treatment of gastrointestinal cancers. Resection margins are assessed histopathologically for the presence of cancer cells while their concomitant evaluation at molecular level is argued to provide more accurate information on recurrence risk and thus facilitate the clinical decision-making [53,54]. It has been pointed out [55] that unraveling molecular alterations in still non-transformed, tumor-adjacent tissue may allow for better understanding of the processes leading to malignancy than the analysis of changes occurring in already transformed cells. In further perspective, it may facilitate developing strategies for their earlier detection and for primary chemoprevention [55]. As we have encountered also in our earlier research [56-58], the exclusive analysis of expression ratio might be inaccurate because of tumor and adjacent tissue being similarly affected. Here, it was best exemplified by lack of association between fold-change in IL-13 protein concentration and ESCC or GC pathology as interleukin level changed along with the disease advancement to similar degree in cancerous and non-cancerous tissue.

The analysis of interleukin expression separately in tumor and adjacent tissue allowed us to demonstrate also the differences with respect to the anatomical sites. Higher levels of IL4, IL4Ra, and IL13Ra1 mRNA expression were detected in gastric than colorectal cancer, which, taking into account their association with tumor progression and aggressiveness may contribute to worse prognosis associated with gastric cancers. As compared to colorectal cancers, both gastric and esophageal cancers have substantially shorter survival rates and higher prevalence of poorly differentiated cancers (G3) [59]. Still, the observations made at mRNA level were in opposition to those made for IL-4 protein, as its protein concentration was significantly higher in CRC than GC, both for tumor and adjacent tissue. In turn, IL13 mRNA was lower in GC than CRC tumors while IL-13 protein was more markedly expressed in GC than CRC. It has been pointed out [60] that lack of association, or poor correlation, between transcript number and protein abundance is quite a common occurrence. It has 
been attributed to a complicated process of protein translation followed by various modifications to synthesized proteins as well as to the substantial differences in mRNA and protein half-life, frequently leading to protein accumulation while respective transcripts have been degraded. Therefore, treating data on mRNA and protein as separate information sources has been encouraged [60].

As there is no consensus concerning interleukins effect on cancer cells in vitro, we assessed their impact on two basic cell activities, that is, viability (net result of proliferation and survival) and mobility. We found IL-4 and IL-13 to improve both; yet, to different degrees, depending on colonic cell line. Others, however, have shown HT-29 cells to respond to IL-4 with reduced proliferation [28,29]. Of note, an anti-proliferative activity has been demonstrated also in gastric [30] and other epithelial cancers [29,61,62]. Still, Liu et al. [17] demonstrated that both IL-4 and IL-13 increase colon cell proliferation via upregulating expression of NADPH oxidase (NOX)-1 and generation of reactive oxygen species. A pro-proliferative activity of IL-4 toward HT-29 and HCT 116 cells was reported by Keller et al. [20]. In turn, pro-proliferative activity of IL-13 toward HT-29 was recently corroborated by Matsui et al. [18]. The results of Chang et al. [28] implicated that the dual IL-4 effect on proliferation might depend on whether the interleukin activates STAT1 (anti-proliferative) or STAT6 (pro-proliferative) as previously found in helper T cells [63]. Others, however, have shown IL4-induced STAT6 activation to be involved in growth inhibition [61]. In this study, growth-promoting activity of IL-4 was observed in HT-29 as well as HCT 116 and Caco-2, but the interleukin increased cell density only by several to twenty percent. Moreover, the stimulatory effect in HT-29 and Caco-2 could be observed after short incubation, like reported by Koller et al. [20], who stimulated cells for $24 \mathrm{~h}$. Prolonged treatment, in turn, especially with high interleukin concentration, tended to be associated with growth inhibition, as demonstrated during 3-day stimulation by Chang et al. [28]. The SRB assay used in this study determines the protein content and therefore the cell density, which might indicate the accelerated proliferation or reduced apoptosis or being the result of both. Here, only IL4Ra correlated with the proliferation marker Ki67 in clinical samples but the association was negative. Negative effect on Ki67 expression had also a stimulation of Caco-2 cells with IL-4. Still, the marker was upregulated, although weakly, in HCT 116 cells stimulated with IL-4 and HT-29 cells stimulated with IL-13. IL-4 is reportedly conferring cancer cells protection against apoptosis. Neutralizing antibodies to IL-4 have inhibited tumor growth in xenograft models by reducing expression of anti-apoptotic Bcl-xL and Bcl-2 [12]. Anti-apoptotic activity of IL-4 has been confirmed also in thyroid [64], lung, and breast cancer [12]. Importantly, anti-apoptotic activity of IL-4 has been associated with an autocrine mode of action [12]. As already mentioned, the cell lines tested did not express IL4 or IL13. Therefore, it may contribute to mostly negative impact of IL- 4 or IL-13 on BCL2 and BCLxL expression.

The similar results of growth promotion were obtained in this study when cancer cells were treated with IL-4 under nutritional stress conditions. The metabolic reprogramming, a recently recognized hallmark of cancer [5], ensures growth advantage over non-transformed and immune cells and promotes cancer cell survival. IL-4 is known to accelerate glucose and glutamine up-take and enhance their metabolism in immune cells and has recently been demonstrated to partake in metabolic reprogramming of breast cancer cells as well [33]. However, our results do not support IL-4 or IL-13 contribution to metabolic reprogramming in CRC. The expression of glucose transporter GLUT1 was rather downregulated in Caco-2 and HCT 116 cells stimulated with IL-4 and its expression in clinical samples was negatively correlated with IL13.

Koller et al. [20] reported that pro-proliferative effects are dominant for IL-4 stimulation of colon cancer cells as only HCT 116 and neither HT-29 nor SW620 responded to IL-4 with enhanced survival. The growth dynamics observed in our study, particularly the difference between HCT 116 and Caco-2 or HT-29 cells at 72-h incubation, might therefore be explained by the weakening of the pro-proliferative effect with prolonged stimulation and, exclusively in HCT 116, by line response to pro-survival activity of IL-4. Especially, that growth-stimulating effect of the interleukin on HCT 116 cells was slightly stronger in cells grown under nutritional stress conditions. Interestingly, the growth-supporting effect on HCT 116 cells under nutritional stress conditions was stronger for IL-13 than IL-4. Both 
interleukins may signal through the same type II IL-4 receptor and elicit similar responses, like was the case in present study, although the sensitivity of examined cell lines differed. In addition to already mentioned slightly greater sensitivity of HCT 116 to pro-survival activity of IL-13 during prolonged stimulation, the migratory properties of those cells were more markedly improved by IL-4. Caco-2 cells, in turn, seemed to respond better to IL-13. Of note, Caco-2 response to IL-4 seem to differ from that observed in HCT 116 and HT-29 also concerning BCL2 and Ki67 expression, down-regulated in Caco-2 but slightly upregulated in HCT 116 and HT-29. Moreover, unlike in immune cells [31], IL-4 stimulation downregulated its receptor expression in Caco-2 cells but not HCT 116 and HT-29. Dissimilar responses might be partly explained by different expression level of IL-4 receptor. Indeed, Caco-2 had significantly higher IL4Ra expression than HCT 116 cells.

As mentioned earlier, Chen et al. [52] implicated E2F1/SP3/STAT6 axis and transcription factors Zeb in the epithelial-mesenchymal transition induced by IL-4. Here, we evaluated IL-4 and IL-13 effect on genes encoding mesenchymal marker, ACTA2, and tight junction proteins ZO-1 (TJP1) (epithelial marker) and claudin-2 (CLDN2). Tight junction proteins preserve cell adhesiveness and prevent dissociation of tumor cells and thus cancer metastasis. Their aberrant expression patterns have been repeatedly noted in epithelial cancers [65]. Disruptive properties of IL-4 and IL-13 on epithelial barrier integrity have been reported. Specifically, the interleukins have been shown to upregulate claudin-2 and downregulate ZO-1 in colonic cancer cell line T84 and airway epithelium, respectively [66,67]. Correspondingly, we found that colonic cancer cells responded to IL-4 and IL-13 stimulation with upregulation of CLDN2, significantly so in case of IL-4, while ACTA2 and TJP1 tended to be rather downregulated, significantly so in case of Caco-2 stimulation with IL-4. However, in clinical samples, heterogeneous with respect to cellular composition, interleukin receptor expression was positively correlated with both ACTA2 and TJP1.

Our study has several limitations that need to be addressed. First, we aimed at quantitative analysis and used appropriate methodology (immunoassays and RTqPCR), which, however, does not allow for indicating cellular origins. As such, lack of complementary immunohistochemistry data may be viewed as a limitation. Second, the in vitro part of our study has an exploratory character aimed at screening for potential associations to select points of interest for future in-depth functional studies discerning signaling pathways involved. As the screening was conducted using transcriptional analysis, our results ought to be confirmed on protein level.

\section{Materials and Methods}

\subsection{Patients}

\subsubsection{Study Population for Analysis of Local Interleukin Expression}

The study population consisted of 49 (for protein determination) or 51 (for transcriptional analysis) cancer patients, admitted to the Department of Gastrointestinal and General Surgery of Wroclaw Medical University for curative resection of esophageal squamous cell carcinomas $(n=18 / 16)$ or gastric $(n=14 / 14)$ or colorectal $(n=17 / 21)$ adenocarcinomas. Patients with any severe systemic illness, with gross metastatic disease, or subjected to radio- or chemotherapy were not included. Patients were subjected to standard preoperative evaluation (blood work, physical examination, and imaging techniques, such as ultrasonography, computed tomography and magnetic resonance). Cancers were rated pathologically using 7th edition of the Union for International Cancer Control TNM system. In all cases, the resection margins have been confirmed to be tumor-free. Detailed population characteristics are depicted in Tables 1 and 2.

\subsubsection{Study Population for Determination of Systemic Interleukin Concentration}

The study population consisted of 263 individuals: 36 controls and 93 patients with histologically confirmed squamous cell carcinomas of the esophagus, 31 with histologically confirmed 
adenocarcinomas of the stomach, 32 with histologically confirmed adenocarcinomas of the gastric cardia, and 71 with histologically confirmed adenocarcinomas of the colorectum. All patients were admitted to the Department of Gastrointestinal and General Surgery of Wroclaw Medical University for the disease diagnosis and/or treatment (curative surgery or palliative treatment). Cancers were rated clinically using 7th edition of the Union for International Cancer Control TNM system. Healthy individuals $(n=36)$ were recruited from otherwise healthy outpatients of Research, Science, and Educational Center of Dementia Diseases, Scinawa, Poland suffering from headaches (dementia, neurological disorders, and brain tumors were excluded during diagnostic process) and from blood donors whose sera were provided by the Regional Center of Blood Donation and Therapeutics in Wroclaw, Poland. Detailed population characteristics are depicted in Table 3.

\subsection{Ethical Considerations}

The study protocol was approved by the Medical Ethics Committee of Wroclaw Medical University (signature number: KB 203/2016). The study was conducted in accordance with the Helsinki Declaration of 1975, as revised in 1983, and informed consent was obtained from all study participants.

\subsection{Analytical Methods}

\subsubsection{Local Interleukin Concentration (Protein)}

Patient-matched pairs of postoperatively collected tissue samples from the tumor and from the macroscopically normal tissue adjacent to the tumor (taken approximately $10 \mathrm{~cm}$ from the tumor) were rinsed with PBS, rapidly frozen and stored at $-45^{\circ} \mathrm{C}$ until analysis.

Weighted 10-40 mg fragments were homogenized (2 min, $4.0 \mathrm{~m} / \mathrm{s})$ in $10 \mathrm{mM}$ Tris-HCl buffer with $150 \mathrm{mM} \mathrm{KCl}$ and $1 \mathrm{mM}$ EDTA, pH 7.4 in proportion 1:2 (w/v) with ceramic spheres and FastPrep-24 homogenizer (MP Biomedical, Solon, OH, USA). Tissue homogenates were centrifuged $\left(14,500 \times g, 10 \mathrm{~min}, 6^{\circ} \mathrm{C}\right)$ and the resulting supernatants were used for interleukin determination.

IL-4 and IL-13 concentrations in clarified tissue homogenates were measured immunoenzymatically using respective Quantikine high-sensitive (HS) ELISA assays for human IL-4 and IL-13, purchased from RnD Systems (Minneapolis, MN, USA). The assays were performed according to manufacturers' instructions. All measurements were conducted in duplicates. Data are expressed as pg (IL-4) or ng (IL-13) of protein per gram of analyzed tissue.

\subsubsection{Systemic Interleukin Concentration}

Peripheral blood was collected into BD Vacutainer CAT tubes (Becton Dickinson, Plymouth, UK), clotted for $30 \mathrm{~min}$ at room temperature and subsequently centrifuged at $1500 \times g$ for $10 \mathrm{~min}$ at room temperature. Obtained sera were aliquoted and stored at $-45^{\circ} \mathrm{C}$ until examination. Blood samples were collected upon admission, prior to any treatment, following overnight fast.

Serum concentrations of IL-4 and IL-13 were measured using immunofluorescence on the BioPlex 200 platform with HRF (Bio-Rad, Hercules, CA, USA), incorporating Luminex xMAP ${ }^{\circledR}$ technology, and Bio-Plex Pro ${ }^{\mathrm{TM}}$ Human Cytokine, Chemokine, and Growth Factor Magnetic Bead-Based Assays. The method is based on flow cytometry. It utilizes magnetic microspheres conjugated with monoclonal antibodies. All analyses were conducted in duplicates and according to the manufacturer's instructions. Standard curves were drawn using 5-PL logistic regression and the data were analyzed using BioPlex Manager 6.0 software.

\subsubsection{Transcriptomic Analysis}

Intraoperatively collected tissue specimens (paired, patient-matched tumor and macroscopically normal samples) were rinsed with PBS, soaked in RNAlater (Ambion Inc., Austin, TX, USA) and stored at $-80{ }^{\circ} \mathrm{C}$ until RNA isolation. 
Tissue samples (up-to $40 \mathrm{mg}$ ) were homogenized using Fastprep 24 Homogenizer (MP Biomedical, Solon, OH, USA) in lysis buffer (provided as a part of PureLink ${ }^{\mathrm{TM}}$ RNA Mini Kit) with addition of $\beta$-mercaptoethanol (Sigma-Aldrich, St. Luis, MO, USA).

Upon termination of cell culture experiments, cells were scratched and lysed with $1 \mathrm{~mL}$ of TRIzol Reagent (Thermo-Fisher Scientific, Waltham, MA, USA) and stored at $-80^{\circ} \mathrm{C}$ until RNA isolation.

RNA from tissue samples and cell cultures was isolated using phenol-chloroform extraction and subsequently purified using PureLink ${ }^{\mathrm{TM}}$ RNA Mini Kit (Thermo-Fisher Scientific). Genomic DNA was removed by on-column treatment of RNA isolates with DNase (PureLink ${ }^{\mathrm{TM}}$ DNase Set, Thermo-Fisher Scientific). The concentration of isolated RNA was quantified using NanoDrop 2000 (Thermo-Fisher Scientific) with concomitant evaluation of RNA purity (ratios of absorbance at 260, 280, and $230 \mathrm{~nm}$ ). RNA integrity was evaluated using the Experion platform incorporating LabChip microfluidic technology and Experion RNA StdSens analysis kits (BioRad) and expressed as RNA quality indicator (RQI) score with $\mathrm{RQI}=1$ indicative of degraded and $\mathrm{RQI}=10$ of intact RNA. Only RNA isolates with RQI $\geq 7$ were used for reversely transcribed quantitative polymerize chain reaction (RT-qPCR).

The $1000 \mathrm{ng}$ of RNA per reaction mixture $(20 \mu \mathrm{L})$ was reversely transcribed in $\mathrm{C} 1000$ termocycler (BioRad) using iScript ${ }^{\mathrm{TM}} \mathrm{cDNA}$ Synthesis Kit (BioRad) and the protocol suggested by manufacturer. Samples were accompanied by matching negative transcription ("no-RT") controls, devoid of reverse transcriptase, subsequently tested to assure lack of contamination with genomic DNA.

Quantitative PCRs were conducted using CFX96 Real-Time PCR system (BioRad) and SsoFast EvaGreen ${ }^{\circledR}$ Supermix (BioRad). The following cycling conditions were applied: $30 \mathrm{~s}$ activation at $95^{\circ} \mathrm{C}, 5 \mathrm{~s}$ denaturation at $95^{\circ} \mathrm{C}$, annealing/extension for $5 \mathrm{~s}$ at $61^{\circ} \mathrm{C}, 40$ cycles, followed by melting step $\left(60-95^{\circ} \mathrm{C}\right.$ with fluorescent reading every $0.5^{\circ} \mathrm{C}$ ). Reaction mixture contained $2 \mu \mathrm{L}$ of cDNA (diluted 1:5), $10 \mu \mathrm{L}$ of $2 \times$ SsoFast EvaGreen ${ }^{\circledR}$ Supermix, $1 \mu \mathrm{L}$ of each $10 \mathrm{nM}$ forward and reverse target-specific primers, and water up to $20 \mu \mathrm{L}$. Only primers spanning at least one intron were used. Their specificities were tested by melting curve analysis and an electrophoresis in a high-resolution agarose (SeaKem LE agarose from Lonza, Basel, Switzerland) in TBE with SYBR Green (Lonza) detection. Only primers yielding a single peak in melt curve and a single band in gel electrophoresis were used. Primers were also tested on no-RT samples with known contamination with gDNA and only these not amplifying gDNA at all or with no-RT signal at least 10 cycles apart from sample signal were selected. Primers were synthesized by Genomed (Warsaw, Poland) and their sequences are presented in Table 12.

Technical replicates were averaged prior analysis. Geometric mean of all $\mathrm{Cq}$ values in a given analysis was obtained and subtracted from sample $\mathrm{Cq}(\Delta \mathrm{Cq})$ then linearized by $2^{\wedge \mathrm{Cq}}$ conversion and normalized to GAPDH. The obtained values are referred to as a normalized relative quantity (NRQ) [68] and subjected to statistical analysis. For paired sample analysis, $\Delta \mathrm{Cq}$ values obtained for normal and pathological tissue or treated and untreated cells were subtracted $(\Delta \Delta \mathrm{Cq})$ and the relative level of expression (fold change in expression) was calculated as $2^{\wedge(-\Delta \Delta \mathrm{Cq})}$.

Table 12. Primers' sequences.

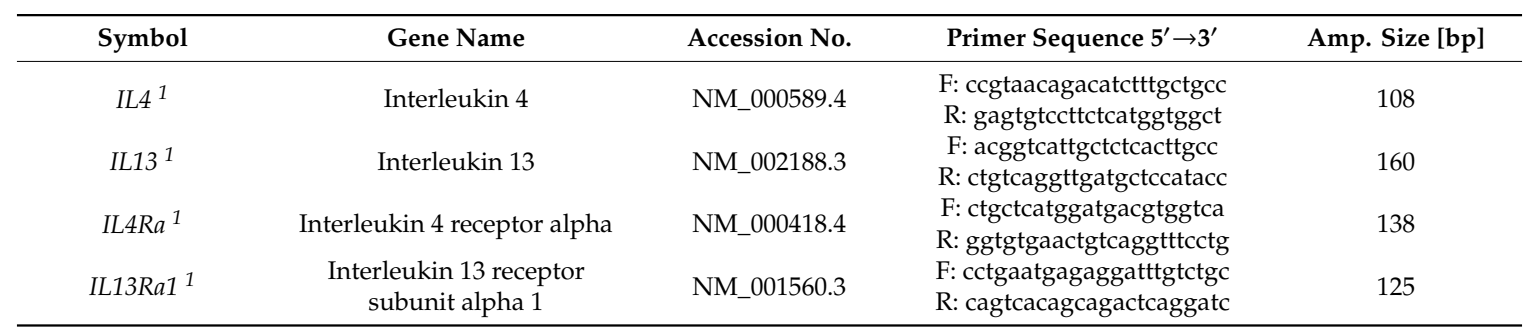


Table 12. Cont.

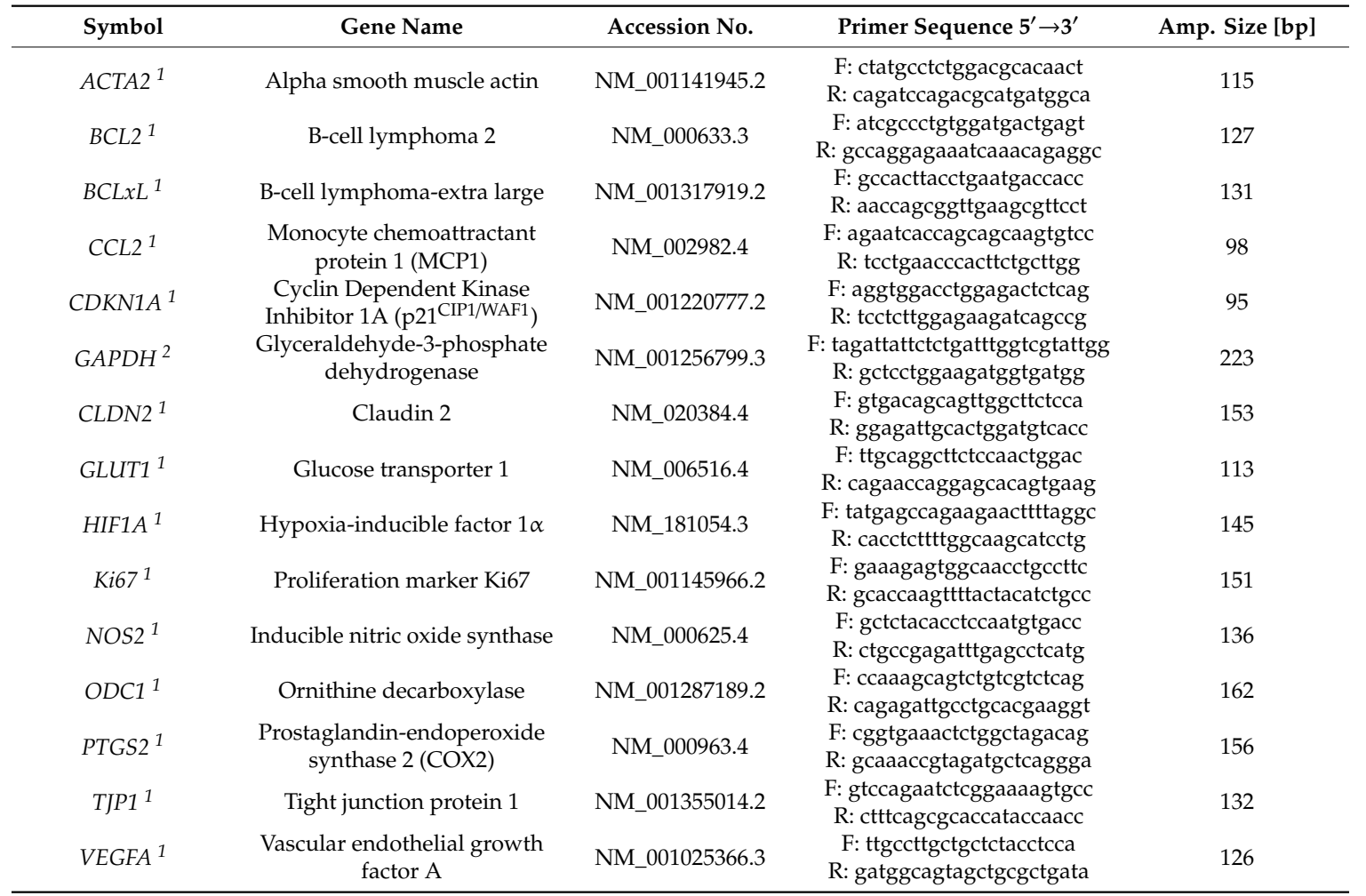

Amp., amplicon; ${ }^{1}$, primer sequences were as proposed by Origene (www.origene.com); ${ }^{2}$, primers were designed using Beacon Designer Probe/Primer Design Software (BioRad), validated in silico by Blast analysis, and their specificity tested by means of melting curve analysis and an electrophoresis in a high-resolution agarose. Forward and reverse primer sequences are denoted by " $F$ " and " $R$ ", respectively.

\subsubsection{Cell Cultures and Cell Culture Experiments}

Certified human adherent colon cancer cell lines: Caco-2 (ATCC ${ }^{\circledR}$ HTB-37'M), HCT 116 (ATCC ${ }^{\circledR}$ CCL-247"M) and HT-29 (ATCC ${ }^{\circledR}$ HTB-38 ${ }^{\mathrm{TM}}$ ) were purchased from ATCC (MD, USA). Cells were cultured in $75 \mathrm{~cm}^{2}$ cell culture flasks (Nunc ${ }^{\mathrm{TM}}$ EasYFlask ${ }^{\mathrm{TM}}$ Nunclon $^{\mathrm{TM}}$ Delta Surface; Thermo Fisher Scientific, Waltham, MA, USA) at $37{ }^{\circ} \mathrm{C}$ in $95 \%$ air with $5 \% \mathrm{CO}_{2}$ in CELCULTURE ${ }^{\circledR}$ CCL-170B-8 incubator (Esco, Singapore), in Dulbecco's modified eagle medium (DMEM; Gibco, Thermo Fisher Scientific), supplemented with 10\% fetal bovine serum (Gibco), 1\% GlutaMAX ${ }^{\mathrm{TM}}-\mathrm{I}$ (Gibco), and with $1 \%$ stabilized antibiotic antimycotic solution (10,000 units penicillin/mL, $10 \mathrm{mg}$ streptomycin/mL, $25 \mu \mathrm{g}$ amphotericin $\mathrm{B} / \mathrm{mL}$; Sigma Aldrich, St. Louis, MO, USA). Medium was renewed in every 3 days. Cells were harvested with TrypLE ${ }^{\text {TM }}$ Express (Gibco) after rinsing with Dulbecco's Phosphate Buffered Saline (DPBS; Gibco). Cells were counted with Countess ${ }^{\mathrm{TM}}$ Automated Cell Counter (Invitrogen, Thermo Fisher Scientific, Waltham, CA, USA) after staining with $0.4 \%$ trypan blue solution (Invitrogen).

Sulforhodamine B (SRB) Viability Assay

Cells were seeded at 1.5-2 $\times 10^{4}$ cells/well on a 96-well plate in three to five technical replicates. For specified times (6 (only for IL-4), 24, 48, or $72 \mathrm{~h}$ ), cells were treated with recombinant human IL-4 or IL-13 (RnD Systems, Minneapolis, MN, USA) in culture medium at concentration of 0 (control) 5, 20,100 , or $250 \mathrm{ng} / \mathrm{mL}$. The experiments were conducted under normal growth conditions (medium supplemented with $10 \%$ FBS) and under nutritional stress (medium supplemented with $0.5 \%$ FBS). After specified incubation time, cells were fixed by gentle addition of cold trichloroacetic acid (Sigma-Aldrich) directly into culture medium to the final concentration of $12.5 \%$. After 1 -h incubation at $4{ }^{\circ} \mathrm{C}$, plates were washed with cold water, dried and $0.04 \%$ SRB in $1 \%$ acetic acid solution (Sigma-Aldrich) was added for 30-min incubation at room temperature. The unbound dye was rinsed with $1 \%$ acetic 
acid while the protein-bound SRB was solubilized by addition of $10 \mathrm{mM}$ Tris base solution (pH 10.5). The absorbance, proportional to protein content, was measured at $492 \mathrm{~nm}$ using Infinite M200 plate spectrophotometer (Tecan Group Ltd., Männedorf, Switzerland). The experiments were conducted at least three times.

\section{Scratch Assay}

The $70 \mu \mathrm{L}$ of cell suspension containing $5 \times 10^{4}$ cells was applied into each well of the Culture-Insert 2 Well (placed in 24-well cell culture plate; Ibidi, Gräfelfing, Germany) and cultured for $24 \mathrm{~h}$. Subsequently, the inserts were removed from wells and wells were rinsed with DPBS, followed by the addition of medium without or with $100 \mathrm{ng} / \mathrm{mL}$ of IL-4 or IL-13. The closure of insert-created gap (wound) was observed in three (Caco-2) or four (HCT 116) independent experiments after 24, 48, and $72 \mathrm{~h}$ under the CKX41 inverted microscope with SC30 camera (Olympus, Tokyo, Japan). For HT-29 cells, the experiment was conducted up-to $144 \mathrm{~h}$ and exclusively for IL-4. Gap area was measured using the MRI Wound Healing Tool macro for ImageJ software (NIH) [69]. Subsequently, the ratios of measured gap areas were calculated (area at a given time point/area at time 0) and statistically compared between stimulated and unstimulated cells. Additionally, mean gap areas (expressed as a percent of gap area at time $0 \mathrm{~h}$ ) were plotted against time.

\section{Cell Culturing for Transcriptional Analysis}

For gene expression analysis, $2 \times 10^{5}$ cells/well were seeded on plastic, flat bottom, 6 -well plates (Corning CellBIND surface) and cultured at $37{ }^{\circ} \mathrm{C}$ in a humidified atmosphere containing $5 \% \mathrm{CO}_{2}$ until 80\% confluence. Subsequently, in serum withdrawal experiment, the complete medium (with $10 \%$ FBS) was replaced with a fresh one with low FBS concentration (0.5\%)-except for control cells (serum-supplemented)-and cells were grown for $24 \mathrm{~h}$. In chemically induced hypoxia experiment, the complete medium was replaced with a fresh one containing $200 \mu \mathrm{M} \mathrm{CoCl}{ }_{2}$ (Sigma-Aldrich) for $24 \mathrm{~h}$ and in the experiments evaluating the effect of IL-4 or IL-13 stimulation, medium was replaced for $24 \mathrm{~h}$ by a fresh one containing interleukins at $250 \mathrm{ng} / \mathrm{mL}$ concentration. Following medium removal, treated and untreated (control) cells were lysed with Trizol (Thermo-Fisher Scientific) and stored at $-80{ }^{\circ} \mathrm{C}$ until RNA isolation.

\subsubsection{Statistical Analysis}

Data were tested for normality of distribution and homogeneity of variances using Kolmogorov-Smirnov test and Levene test, respectively. Paired data were analyzed using $t$-test for paired samples. Two-group comparisons were conducted using $t$-test for independent samples, with Welch correction in case of unequal variances. Resulting data are presented as means/geometric means with 95\% confidence interval (CI). Multigroup comparisons were conducted using one-way ANOVA, following log-transformation if suitable, with Tukey-Kramer post-hoc test or Kruskal-Wallis $H$ test with Conover post-hoc test. Resulting data are presented as, respectively, geometric means or medians with $95 \%$ CI. The $t$-test for one mean and comparison of rates were used to analyze in vitro data. Frequency analysis was conducted using $\chi^{2}$ test while correlation analysis using Spearman's rank correlation test $(\rho)$ or Pearson correlation $(r)$ as indicated. All calculated probabilities were two-tailed. The $p$ values $\leq 0.05$ were considered statistically significant. The entire analysis was conducted using MedCalc Statistical Software version 19.2 (MedCalc Software Ltd., Ostend, Belgium; https://www.medcalc.org; 2020).

\section{Conclusions}

Colorectal as well as upper gastrointestinal tract tumors have higher concentration of IL-4 and IL-13 than adjacent non-cancerous tissue, which, solely in CRC tumors, is accompanied by elevated expression of IL13 transcripts. Local expression of ILs and their receptors reflect cancer pathology in a cancer type-depended manner. Specifically, the elevation of IL-4 in gastric tumors (protein and 
mRNA) is directly proportional to the disease advancement. In ESCC and CRC, in turn, the more advanced and aggressive disease, the less IL-4 protein and mRNA are present and the alterations occur in non-cancerous adjacent tissue rather than in tumor. The observation concerning differences in expression levels with respect to the anatomical site as well as to whether they concern protein or mRNA transcripts ought to be taken into account while planning immunotherapies affecting IL-4/IL-4R and IL-13/IL-13R pathways. Finding on altered IL/ILR expression in non-cancerous tissue adds to the increasing knowledge on tumor molecular margin and is potentially relevant for clinical decision-making.

We found that receptor expression in colonic cell lines is negatively affected by hypoxia, what seems to support antiangiogenic role of IL-4/IL4R axis. Still, receptor expression in clinical tumor samples is correlated positively with a number of genes encoding proteins relevant for cancer development and progression. However, with few exceptions, observations made for clinical samples do not translate into cause-effect relationship in vitro. Stimulation with exogenous ILs slightly improves colonic cell viability, accompanied by marginal upregulation of proliferation marker Ki67 and anti-apoptotic BCL2 in HCT 116 and HT-29 cells. It has a more marked effect on cell motility, accompanied by consistent upregulation of $C L D N 2$, encoding tight junction protein claudin-2, and, significantly so in Caco-2 cells, by the downregulation of epithelial marker TJP1. Further research is needed to confirm the associations observed here on protein level and to elucidate involved signaling pathways.

Author Contributions: Conceptualization, I.B.-M., D.D., and M.K.-K.; data curation, D.D. and J.R.; formal analysis, I.B.-M., I.S., and M.K.-K.; funding acquisition, D.D., J.R., and M.K.-K.; investigation, I.B.-M., D.D., I.S., P.F., A.K., and M.K.-K.; methodology, I.B.-M. and M.K.-K.; project administration, M.K.-K.; resources, M.K.-K.; supervision, J.R. and M.K.-K.; visualization, I.B.-M., I.S., and M.K.-K.; writing—original draft, I.B.-M., and M.K.-K.; writing-review and editing, I.B.-M., D.D., I.S., P.F., A.K., J.R., and M.K.-K. All authors have read and agreed to the published version of the manuscript.

Funding: This research was funded by Wroclaw Medical University, statutory grant number SUB.A040.19.016.

Acknowledgments: The authors would like to thank the Foundation of Wroclaw Medical University (FAM) and its Board Chairmen for financing a lease of BioRad Experion platform and CFX96 Real-Time PCR system.

Conflicts of Interest: The authors declare no conflict of interest.

\section{Abbreviations}

$\begin{array}{ll}\text { CC } & \text { Adenocarcinoma of gastric cardia } \\ \text { CRC } & \text { Colorectal adenocarcinoma } \\ \text { ESCC } & \text { Esophageal squamous cell carcinoma } \\ \text { FBS } & \text { Fetal bovine serum } \\ \text { GC } & \text { Gastric adenocarcinoma } \\ \text { GIT } & \text { Gastrointestinal tract } \\ \text { IL } & \text { Interleukin } \\ \text { EMT } & \text { Epithelial-mesenchymal transition } \\ \text { NRQSRB } & \text { Normalized relative quantitiesSulforhodamine B } \\ \text { TNM } & \text { Tumor-node-metastasis grading system }\end{array}$

\section{References}

1. Bray, F.; Ferlay, J.; Soerjomataram, I.; Siegel, R.L.; Torre, L.A.; Jemal, A. Global cancer statistics 2018: GLOBOCAN estimates of incidence and mortality worldwide for 36 cancers in 185 countries. CA Cancer J. Clin. 2018, 68, 394-424. [CrossRef] [PubMed]

2. Grierson, P.; Lim, K.-H.; Amin, M. Immunotherapy in gastrointestinal cancers. J. Gastrointest. Oncol. 2017, 8, 474-484. [CrossRef] [PubMed]

3. Bever, K.M.; Le, D.T. An expanding role for immunotherapy in colorectal cancer. J. Natl. Compr. Canc. Netw. 2017, 15, 401-410. [CrossRef] [PubMed]

4. Rabinovich, G.A.; Gabrilovich, D.; Sotomayor, E.M. Immunosuppressive strategies that are mediated by tumor cells. Annu. Rev. Immunol. 2007, 25, 267-296. [CrossRef] [PubMed] 
5. Hanahan, D.; Weinberg, R.A. Hallmarks of cancer: The next generation. Cell 2011, 144, 646-674. [CrossRef] [PubMed]

6. Monteran, L.; Erez, N. The dark side of fibroblasts: Cancer-associated fibroblasts as mediators of immunosuppression in the tumor microenvironment. Front. Immunol. 2019, 10, 1835. [CrossRef] [PubMed]

7. Hallett, M.A.; Venmar, K.T.; Fingleton, B. Cytokine stimulation of epithelial cancer cells: The similar and divergent functions of IL4 and IL13. Cancer Res. 2012, 72, 6338-6343. [CrossRef]

8. Bankaitis, K.V.; Fingleton, B. Targeting IL4/IL4R for the treatment of epithelial cancer metastasis. Clin. Exp. Metastasis 2015, 32, 847-856. [CrossRef]

9. Zhou, R.; Qian, S.; Gu, X.; Chen, Z.; Xiang, J. Interleukin-13 and its receptors in colorectal cancer (Review). Biomed. Rep. 2013, 1, 687-690. [CrossRef]

10. Barderas, S.; Bartolomé, R.A.; Fernandez-Aceñero, M.J.; Torres, S.; Casal, J.I. High expression of IL-13 receptor $\alpha 2$ in colorectal cancer is associated with invasion, liver metastasis, and poor prognosis. Cancer Res. 2012, 72, 2780-2790. [CrossRef]

11. Bartolomé, R.A.; Jaén, M.; Casal, J.I. An IL13R $\alpha 2$ peptide exhibits therapeutic activity against metastatic colorectal cancer. Br. J. Cancer. 2018, 119, 940-949. [CrossRef] [PubMed]

12. Todaro, M.; Lombardo, Y.; Francipane, M.G.; Alea, M.P.; Cammareri, P.; Iovino, F.; Di Stefano, A.B.; Di Bernardo, C.; Agrusa, A.; Condorelli, G.; et al. Apoptosis resistance in epithelial tumors is mediated by tumor-cell-derived interleukin-4. Cell Death Differ. 2008, 15, 762-772. [CrossRef] [PubMed]

13. Song, M.; Rabkin, C.S.; Torres, J.; Kemp, T.J.; Zabaleta, J.; Pinto, L.A.; Hildesheim, A.; Sánchez-Figueroa, L.; Guarner, J.; Herrera-Goepfert, R.; et al. Circulating inflammation-related markers and advanced gastric premalignant lesions. J. Gastroenterol. Hepatol. 2019, 34, 852-856. [CrossRef] [PubMed]

14. Vinagre, R.M.D.F.; Vinagre, I.D.F.; Vilar-E.-Silva, A.; Fecury, A.A.; Martins, L.C. Helicobacter pylori infection and immune profile of patients with different gastroduodenal diseases. Arq. Gastroenterol. 2018, 55, $122-127$. [CrossRef]

15. Diaz Orea, M.A.; Muñoz Perez, V.; Gómez Conde, E.; Castellanos Sánchez, V.O.; Gonzalez Lopez, R.; Flores Alonso, J.C.; Cárdenas, M.E.; Galicia, A.L.; Mendoza, A. Expression of cytokines interleukin-2, interleukin-4, interleukin-10 and transforming growth factor $\beta$ in gastric adenocarcinoma biopsies obtained from mexican patients. Asian Pac. J. Cancer Prev. 2017, 18, 577-582.

16. Lin, C.; Liu, H.; Zhang, H.; He, H.; Li, H.; Shen, Z.; Qin, J.; Qin, X.; Xu, J.; Sun, Y. Interleukin-13 receptor $\alpha 2$ is associated with poor prognosis in patients with gastric cancer after gastrectomy. Oncotarget 2016, 7, 49281-49288. [CrossRef]

17. Liu, H.; Antony, S.; Roy, K.; Juhasz, A.; Wu, Y.; Lu, J.; Meitzler, J.L.; Jiang, G.; Polley, E.; Doroshow, J.H. Interleukin-4 and interleukin-13 increase NADPH oxidase 1-related proliferation of human colon cancer cells. Oncotarget 2017, 8, 38113-38135. [CrossRef]

18. Matsui, S.; Okabayashi, K.; Tsuruta, M.; Shigeta, K.; Seishima, R.; Ishida, T.; Kondo, T.; Suzuki, Y.; Hasegawa, H.; Shimoda, M.; et al. Interleukin-13 and its signaling pathway is associated with obesity-related colorectal tumorigenesis. Cancer Sci. 2019, 110, 2156-2165. [CrossRef]

19. Miska, J.; Lui, J.B.; Toomer, K.H.; Devarajan, P.; Cai, X.; Houghton, J.; Lopez, D.M.; Abreu, M.T.; Wang, G.; Chen, Z. Initiation of inflammatory tumorigenesis by CTLA4 insufficiency due to type 2 cytokines. J. Exp. Med. 2018, 215, 841-858. [CrossRef]

20. Koller, F.L.; Hwang, D.G.; Dozier, E.A.; Fingleton, B. Epithelial interleukin-4 receptor expression promotes colon tumor growth. Carcinogenesis 2010, 31, 1010-1017. [CrossRef]

21. Li, J.; Chen, X.L.; Shaker, A.; Oshima, T.; Shan, J.; Miwa, H.; Feng, C.; Zhang, J. Contribution of immunomodulators to gastroesophageal reflux disease and its complications: Stromal cells, interleukin 4, and adiponectin. Ann. NY Acad. Sci. 2016, 1380, 183-194. [CrossRef] [PubMed]

22. Meyer, A.R.; Goldenring, J.R. Injury, repair, inflammation and metaplasia in the stomach. J. Physiol. 2018, 596, 3861-3867. [CrossRef] [PubMed]

23. Li, J.; Zhang, B.Z.; Qin, Y.R.; Bi, J.; Liu, H.B.; Li, Y.; Cai, M.Y.; Ma, S.; Chan, K.W.; Xie, D.; et al. CD68 and interleukin 13, prospective immune markers for esophageal squamous cell carcinoma prognosis prediction. Oncotarget 2016, 7, 15525-15538. [CrossRef] [PubMed]

24. Saigusa, S.; Tanaka, K.; Inoue, Y.; Toiyama, Y.; Okugawa, Y.; Iwata, T.; Mohri, Y.; Kusunoki, M. Low serum interleukin-13 levels correlate with poorer prognoses for colorectal cancer patients. Int. Surg. 2014, 99, 223-229. [CrossRef] [PubMed] 
25. Essner, R.; Huynh, Y.; Nguyen, T.; Rose, M.; Kojima, M.; Hoon, D.S. Functional interleukin-4 receptor and interleukin-2 receptor common gamma chain in human gastric carcinoma: A possible mechanism for cytokine-based therapy. J. Gastrointest. Surg. 2001, 5, 81-90. [CrossRef]

26. Formentini, A.; Braun, P.; Fricke, H.; Link, K.H.; Henne-Bruns, D.; Kornmann, M. Expression of interleukin-4 and interleukin-13 and their receptors in colorectal cancer. Int. J. Colorectal Dis. 2012, 27, 1369-1376. [CrossRef] [PubMed]

27. Ko, C.W.; Cuthbert, R.J.; Orsi, N.M.; Brooke, D.A.; Perry, S.L.; Markham, A.F.; Coletta, P.L.; Hull, M.A. Lack of interleukin-4 receptor alpha chain-dependent signalling promotes azoxymethane-induced colorectal aberrant crypt focus formation in Balb/c mice. J. Pathol. 2008, 214, 603-609. [CrossRef] [PubMed]

28. Chang, T.L.; Peng, X.; Fu, X.Y. Interleukin-4 mediates cell growth inhibition through activation of Stat1. J. Biol. Chem. 2000, 275, 10212-10217. [CrossRef]

29. Toi, M.; Bicknell, R.; Harris, A.L. Inhibition of colon and breast carcinoma cell growth by interleukin-4. Cancer Res. 1992, 52, 275-279.

30. Morisaki, T.; Uchiyama, A.; Yuzuki, D.; Essner, R.; Morton, D.L.; Hoon, D.S. Interleukin 4 regulates G1 cell cycle progression in gastric carcinoma cells. Cancer Res. 1994, 54, 1113-1118.

31. So, E.-Y.; Park, H.-H.; Lee, C.-E. IFN- $\gamma$ and IFN- $\alpha$ posttranscriptionally down-regulate the IL-4-induced IL-4 receptor gene expression. J. Immunol. 2000, 165, 5472-5479. [CrossRef] [PubMed]

32. Xu, X.T.; Hu, W.T.; Zhou, J.Y.; Tu, Y. Celecoxib enhances the radiosensitivity of HCT116 cells in a COX-2 independent manner by up-regulating BCCIP. Am. J. Transl. Res. 2017, 9, 1088-1100. [PubMed]

33. Venmar, K.T.; Carter, K.J.; Hwang, D.G.; Dozier, E.A.; Fingleton, B. IL4 receptor ILR4 $\alpha$ regulates metastatic colonization by mammary tumors through multiple signaling pathways. Cancer Res. 2014, 74, 4329-4340. [CrossRef] [PubMed]

34. Kelly, J.; Minoda, Y.; Meredith, T.; Cameron, G.; Philipp, M.S.; Pellicci, D.G.; Corbett, A.J.; Kurts, C.; Gray, D.H.; Godfrey, D.I.; et al. Chronically stimulated human MAIT cells are unexpectedly potent IL-13 producers. Immuno. Cell Biol. 2019, 97, 689-699. [CrossRef] [PubMed]

35. Dougan, M.; Dranoff, G.; Dougan, S.K. Cancer immunotherapy: Beyond checkpoint blockade. Annu. Rev. Cancer Biol. 2019, 3, 4.1-4.21. [CrossRef]

36. von Bernstorff, W.; Voss, M.; Freichel, S.; Schmid, A.; Vogel, I.; Jöhnk, C.; Henne-Bruns, D.; Kremer, B.; Kalthoff, H. Systemic and local immunosuppression in pancreatic cancer patients. Clin. Cancer Res. 2001, 7 (Suppl. 3), 925s-932s.

37. Cárdenas, D.M.; Sánchez, A.C.; Rosas, D.A.; Rivero, E.; Paparoni, M.D.; Cruz, M.A.; Suárez, Y.P.; Galvis, N.F. Preliminary analysis of single-nucleotide polymorphisms in IL-10, IL-4, and IL-4R $\alpha$ genes and profile of circulating cytokines in patients with gastric Cancer. BMC Gastroenterol. 2018, 18, 184. [CrossRef]

38. Kim, Y.W.; Kim, S.K.; Kim, C.S.; Kim, I.Y.; Cho, M.Y.; Kim, N.K. Association of serum and intratumoral cytokine profiles with tumor stage and neutrophil lymphocyte ratio in colorectal cancer. Anticancer Res. 2014, $34,3481-3487$.

39. Krzystek-Korpacka, M.; Zawadzki, M.; Kapturkiewicz, B.; Lewandowska, P.; Bednarz-Misa, I.; Gorska, S.; Witkiewicz, W.; Gamian, A. Subsite heterogeneity in the profiles of circulating cytokines in colorectal cancer. Cytokine 2018, 110, 435-441. [CrossRef]

40. Yamaguchi, M.; Okamura, S.; Yamaji, T.; Iwasaki, M.; Tsugane, S.; Shetty, V.; Koizumi, T. Plasma cytokine levels and the presence of colorectal cancer. PLoS ONE 2019, 14, e0213602. [CrossRef]

41. Johdi, N.A.; Mazlan, L.; Sagap, I.; Jamal, R. Profiling of cytokines, chemokines and other soluble proteins as a potential biomarker in colorectal cancer and polyps. Cytokine 2017, 99, 35-42. [CrossRef] [PubMed]

42. Olsen, R.S.; Nijm, J.; Andersson, R.E.; Dimberg, J.; Wågsäter, D. Circulating inflammatory factors associated with worse long-term prognosis in colorectal cancer. World. J. Gastroenterol. 2017, 23, 6212-6219. [CrossRef] [PubMed]

43. Wong, R. Proximal tumors are associated with greater mortality in colon cancer. J. Gen. Intern. Med. 2010, 25, 1157-1163. [CrossRef] [PubMed]

44. Huang, C.W.; Tsai, H.L.; Huang, M.Y.; Huang, C.M.; Yeh, Y.S.; Ma, C.J.; Wang, J.Y. Different clinicopathologic features and favorable outcomes of patients with stage III left-sided colon cancer. World J. Surg. Oncol. 2015, 13, 257. 
45. Moritani, K.; Hasegawa, H.; Okabayashi, K.; Ishii, Y.; Endo, T.; Kitagawa, Y. Difference in the recurrence rate between right- and left-sided colon cancer: A 17-year experience at a single institution. Surg. Today 2014, 44, 1685-1691. [CrossRef] [PubMed]

46. Neubauer, K.; Matusiewicz, M.; Bednarz-Misa, I.; Gorska, S.; Gamian, A.; Krzystek-Korpacka, M. Diagnostic potential of systemic eosinophil-associated cytokines and growth factors in IBD. Gastroenterol. Res. Pract. 2018, 2018, 7265812. [CrossRef]

47. Gabitass, R.F.; Annels, N.E.; Stocken, D.D.; Pandha, H.A.; Middleton, G.W. Elevated myeloid-derived suppressor cells in pancreatic, esophageal and gastric cancer are an independent prognostic factor and are associated with significant elevation of the Th2 cytokine interleukin-13. Cancer Immunol. Immunother. 2011, 60, 1419-1430. [CrossRef]

48. Xin, Z.; Wenyu, F.; Shenhua, X. Clinicopathologic significance of cytokine levels in esophageal squamous cell carcinoma. Hepatogastroenterology 2010, 57, 1416-1422.

49. Zou, Z.; Zhao, L.; Su, S.; Liu, Q.; Yu, L.; Wei, J.; Yang, Y.; Du, J.; Shen, J.; Qian, X.; et al. The plasma levels of 12 cytokines and growth factors in patients with gastric cancer. Medicine (Baltimore) 2018, 97, e0413. [CrossRef]

50. Zhang, J.; Patel, L.; Pienta, K.J. CC chemokine ligand 2 (CCL2) promotes prostate cancer tumorigenesis and metastasis. Cytokine Growth Factor Rev. 2010, 21, 41-48. [CrossRef]

51. Cui, X.; Yang, S.C.; Sharma, S.; Heuze-Vourch, N.; Dubinett, S.M. IL-4 regulates COX-2 and PGE2 production in human non-small cell lung cancer. Biochem. Biophys. Res. Commun. 2006, 343, 995-1001. [CrossRef] [PubMed]

52. Chen, J.; Gong, C.; Mao, H.; Li, Z.; Fang, Z.; Chen, Q.; Lin, M.; Jiang, X.; Hu, Y.; Wang, W.; et al. E2F1/SP3/STAT6 axis is required for IL-4-induced epithelial-mesenchymal transition of colorectal cancer cells. Int. J. Oncol. 2018, 53, 567-578. [CrossRef] [PubMed]

53. Mao, L.; Clark, D. Molecular margin of surgical resections-where do we go from here? Cancer 2015, 121, 1914-1916. [CrossRef] [PubMed]

54. Dakubo, G.D.; Jakupciak, J.P.; Birch-Machin, M.A.; Parr, R.L. Clinical implications and utility of field cancerization. Cancer Cell. Int. 2007, 7, 2. [CrossRef] [PubMed]

55. Patel, A.; Tripathi, G.; Gopalakrishnan, K.; Williams, N.; Arasaradnam, R.P. Field cancerisation in colorectal cancer: A new frontier or pastures past? World J. Gastroenterol. 2015, 21, 3763-3772. [CrossRef]

56. Neubauer, K.; Bednarz-Misa, I.; Diakowska, D.; Kapturkiewicz, B.; Gamian, A.; Krzystek-Korpacka, M. $\mathrm{Nampt} / \mathrm{PBEF} /$ visfatin upregulation in colorectal tumors, mirrored in normal tissue and whole blood of colorectal cancer patients, is associated with metastasis, hypoxia, IL1 $\beta$, and anemia. Biomed. Res. Int. 2015, 2015, 523930. [CrossRef]

57. Krzystek-Korpacka, M.; Gorska, S.; Diakowska, D.; Kapturkiewicz, B.; Podkowik, M.; Gamian, A.; Bednarz-Misa, I. Midkine is up-regulated in both cancerous and inflamed bowel, reflecting lymph node metastasis in colorectal cancer and clinical activity of ulcerative colitis. Cytokine 2017, 89, 68-75. [CrossRef]

58. Bednarz-Misa, I.; Diakowska, D.; Krzystek-Korpacka, M. Local and systemic IL-7 concentration in gastrointestinal-tract cancers. Medicina 2019, 55, 262. [CrossRef]

59. Schlesinger-Raab, A.; Werner, J.; Friess, H.; Hölzel, D.; Engel, J. Age and outcome in gastrointestinal cancers: A population-based evaluation of oesophageal, gastric and colorectal cancer. Visc. Med. 2017, 33, 245-253. [CrossRef]

60. Greenbaum, D.; Colangelo, C.; Williams, K.; Gerstein, M. Comparing protein abundance and mRNA expression levels on a genomic scale. Genome Biol. 2003, 4, 117. [CrossRef]

61. Gooch, J.L.; Christy, B.; Yee, D. STAT6 mediates interleukin-4 growth inhibition in human breast cancer cells. Neoplasia 2002, 4, 324-331. [CrossRef] [PubMed]

62. Topp, M.S.; Koenigsmann, M.; Mire-Sluis, A.; Oberberg, D.; Eitelbach, F.; von Marschall, Z.; Notter, M.; Reufi, B.; Stein, H.; Thiel, E.; et al. Recombinant human interleukin-4 inhibits growth of some human lung tumor cell lines in vitro and in vivo. Blood 1993, 82, 2837-2844. [CrossRef] [PubMed]

63. Yu, C.R.; Mahdi, R.M.; Ebong, S.; Vistica, B.P.; Chen, J.; Guo, Y.; Gery, I.; Egwuagu, C.E. Cell proliferation and stat6 pathways are negatively regulated in t cells by stat1 and suppressors of cytokine signaling. J. Immunol. 2004, 173, 737-746. [CrossRef] [PubMed]

64. Vella, V.; Mineo, R.; Frasca, F.; Mazzon, E.; Pandini, G.; Vigneri, R.; Belfiore, A. Interleukin-4 stimulates papillary thyroid cancer cell survival: Implications in patients with thyroid cancer and concomitant Graves' disease. J. Clin. Endocrinol. Metab. 2004, 89, 2880-2889. [CrossRef] 
65. Salvador, E.; Burek, M.; Förster, C.Y. Tight junctions and the tumor microenvironment. Curr. Pathobiol. Rep. 2016, 4, 135-145. [CrossRef] [PubMed]

66. Saatian, B.; Rezaee, F.; Desando, S.; Emo, J.; Chapman, T.; Knowlden, S.; Georas, S.N. Interleukin-4 and interleukin-13 cause barrier dysfunction in human airway epithelial cells. Tissue Barriers 2013, 1, e24333. [CrossRef] [PubMed]

67. Al-Sadi, R.; Boivin, M.; Ma, T. Mechanism of cytokine modulation of epithelial tight junction barrier. Front. Biosci. 2009, 14, 2765-2778. [CrossRef]

68. Hellemans, J.; Vandesompele, J. qPCR data analysis-Unlocking the secret to successful results. In PCR Troubleshooting and Optimization: The Essential Guide, 1st ed.; Kennedy, S., Oswald, N., Eds.; Caister Academic Press: Poole, UK, 2011; pp. 1-13.

69. Tam, S.Y.; Wu, V.W.C.; Law, H.K.W. JNK pathway mediates low oxygen level induced epithelial-mesenchymal transition and stemness maintenance in colorectal cancer cells. Cancers 2020, 12, 224. [CrossRef]

(C) 2020 by the authors. Licensee MDPI, Basel, Switzerland. This article is an open access article distributed under the terms and conditions of the Creative Commons Attribution (CC BY) license (http://creativecommons.org/licenses/by/4.0/). 